\title{
RMetS
}

Royal Meteorological Society

\section{Forecasting summer convection over the Black Forest: a case study from the Convective and Orographically-induced Precipitation Study (COPS) experiment}

\author{
E. Richard, ${ }^{\mathrm{a} \rtimes}$ J.-P. Chaboureau, ${ }^{\mathrm{a}}$ C. Flamant, ${ }^{\mathrm{b}}$ C. Champollion, ${ }^{\mathrm{c}}$ M. Hagen, ${ }^{\mathrm{d}}$ K. Schmidt, ${ }^{\mathrm{d}}$ \\ C. Kiemle, ${ }^{\mathrm{d}}$ U. Corsmeier, ${ }^{\mathrm{e}}$ C. Barthlott ${ }^{\mathrm{e}}$ and P. Di Girolamo ${ }^{\mathrm{f}}$ \\ ${ }^{a}$ Laboratoire d'Aérologie, CNRS and Université de Toulouse III, Toulouse, France \\ ${ }^{\mathrm{b}}$ Laboratoire Atmosphères, Milieux, Observations Spatiales, CNRS and Université de Paris VI, Paris, France \\ ${ }^{\mathrm{C}}$ Géosciences, CNRS and Université de Montpellier II, Montpellier, France \\ ${ }^{\mathrm{d}}$ Deutsches Zentrum für Luft- und Raumfahrt (DLR), Oberpfaffenhofen, Germany \\ 'Institute for Meteorology and Climate Research, Karlsruhe Institute of Technology (KIT), Karlsruhe, Germany \\ ${ }_{\mathrm{f}}^{\mathrm{D}}$ IFA, Università degli Studi della Basilicata, Potenza, Italy \\ ${ }^{\star}$ Correspondence to: E. Richard, Laboratoire d'Aérologie, 14 Avenue Belin, 31400 Toulouse, France. \\ E-mail: Evelyne.Richard@aero.obs-mip.fr
}

In the mid-afternoon of 15 July 2007, during the Convective and Orographicallyinduced Precipitation Study (COPS), in a very warm and dry environment, an isolated, short-lived, deep convective system developed over the southern Black Forest. Most of the high-resolution, convection-permitting models involved in COPS were unable to capture this event whereas the Meso-NH forecast was quite skilful. To assess the Meso-NH performance further, the model results were carefully checked against the various and numerous COPS observations. In full agreement with clear-air radar observations, model results underlined the triggering role of a low-level convergence line that developed in the lee of the Feldberg. The main departure from the observations was found to be in the low-level moisture fields, which appeared significantly moister in the model than in the observations and also slightly moister than in the other models. Sensitivity studies showed that this departure from the observations was strongly controlled by the initial surface moisture conditions. When the surface moisture was reduced by $20 \%$ or replaced by the value derived from a different analysis, the evolution of the planetary boundary layer was more accurately represented while the storm evolution was still correctly captured. These results demonstrate that the quality of the initial forecast cannot be ascribed to the moist bias of the model. It could therefore be hypothesized that the key parameters for a satisfactory forecast of this event lie more in the ability of the model to reproduce the dynamical forcing accurately than in the characteristics of the air-mass instability. Copyright (c) 2011 Royal Meteorological Society

Key Words: orography; surface moisture; water vapour

Received 13 February 2010; Revised 19 July 2010; Accepted 10 September 2010; Published online in Wiley Online Library 6 January 2011

Citation: Richard E, Chaboureau J-P, Flamant C, Champollion C, Hagen M, Schmidt K, Kiemle C, Corsmeier U, Barthlott C, Girolamo PDi. 2011. Forecasting summer convection over the Black Forest: a case study from the Convective and Orographically-induced Precipitation Study (COPS) experiment. Q. J. R. Meteorol. Soc. 137: 101-117. DOI:10.1002/qj.710

1. Introduction

At midlatitudes, it is well established that the skill and accuracy of precipitation forecasts are particularly poor during the summer season (Fritsch and Carbone, 2004). In contrast with the other periods of the year, the warm season exhibits a much higher frequency of convective weather systems, which are not comprehensively resolved 
by current operational models. Whether the presence of topography improves or degrades the forecast skill is not really clear. On the one hand, the preferential locations for convection are more easily captured by the models because the triggering mechanisms are closely linked to the underlying topography (e.g up-slope lifting, lee-side convergence or lee waves induced by small-scale terrain features: Banta, 1990; Cosma et al., 2002; Kirshbaum et al., 2007). On the other hand, the presence of orography makes large demands on the numerics and physics of the models, and may degrade the model skill and introduce artificial biases (Zängl, 2002; Schwitalla et al., 2008).

In recent years, great efforts have been made to tackle the issues related to convective precipitation. Firstly, the field of short-range precipitation forecasting has undergone major development, with the emergence and consolidation of new numerical models solving the full non-hydrostatic set of equations and thus being able, to some extent, to resolve moist convection explicitly. The development of these new models was accompanied by a substantial refinement of most physical parametrizations, especially those devoted to the cloud and precipitation physics. Secondly, a number of field experiments were organized to collect the high-resolution data sets necessary for validation. Each of these experiments had its specific goals and took place over a variety of complex terrains. The Mesoscale Alpine Programme (MAP: Bougeault et al., 2001; Volkert et al., 2007) took place in the Alpine region in the autumn of 1999, with the aim of better understanding the precipitation enhancement over high mountain regions. The International $\mathrm{H}_{2} \mathrm{O}$ Project (IHOP: Weckwerth et al., 2004) was performed in 2002 on relatively flat terrain, mainly focusing on convection initiation. The Convective Storm Initiation Project (CSIP: Browning et al., 2007) also addressed the issue of convection initiation during the summers of 2004 and 2005 over southern England but in a region characterized by a marine environment and very low topography. More recently, the Convective and Orographically-induced Precipitation Study (COPS) took place during summer 2007 over northeastern France and southwestern Germany in a region of moderate orography (Wulfmeyer et al., 2008). In contrast to the previous experiments, the COPS field campaign was accompanied by a huge modelling effort performed in the framework of the MAP-D-PHASE project (Rotach et al., 2009). More than 30 models of various resolutions (including no fewer than a dozen high-resolution convection-permitting models) were run in real time.

The COPS campaign was fairly successful in many aspects (Wulfmeyer et al., 2011), but very few cases of pure airmass convection were observed. Among these, the case of 15 July stood out as a 'golden day' of the experiment, firstly because convection occurred unexpectedly in a very marginally unstable environment and secondly because most of the D-PHASE models were unable to capture the event. Only the Meso-NH research model* and the Météo-France AROME model (run in its pre-operational version) provided an accurate forecast of the storm.

The goal of this article is to assess the Meso$\mathrm{NH}$ performance further by comparing the available observations and the different ingredients that led to the convective development, including the atmospheric

\footnotetext{
*http://mesonh.aero.obs-mip.fr/mesonh/cops/.
}

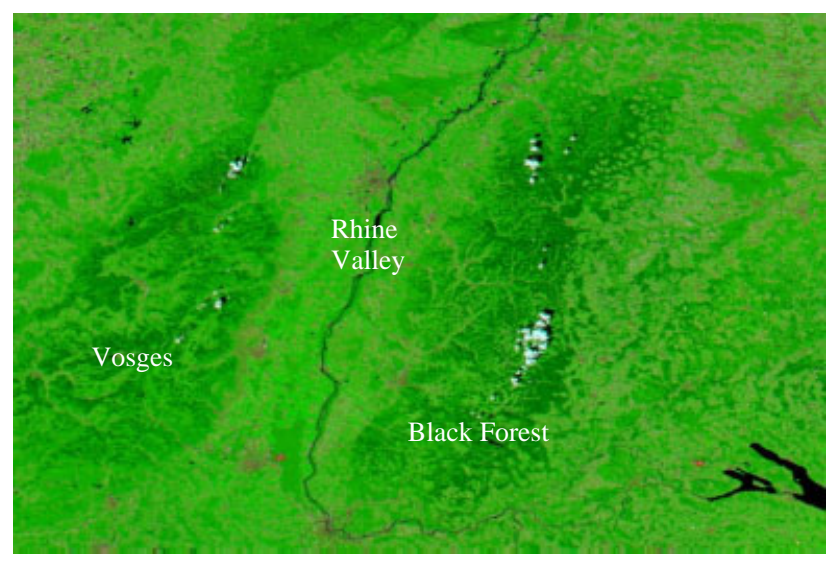

Figure 1. Early phase of development of the convective line over the Black Forest (RGB image of bands 7, 2, 1 of the MODIS instrument on the AQUA satellite, horizontal resolution $250 \mathrm{~m}, 1215 \mathrm{UTC}$ ). This figure is available in colour online at wileyonlinelibrary.com/journal/qj

stability, the moisture supply and the orographic forcing. Then the robustness of the results is investigated from various sensitivity experiments in which initial, surface and boundary conditions are varied.

The article is organized as follows. Section 2 gives a brief overview of the 15 July storm on the basis of satellite and radar observations, while section 3 describes the model and its numerical set-up. In section 4 the results of the control experiment are assessed with respect to the available observations. The sensitivity of these results to different aspects of the initial conditions is tested in section 5 . Conclusions are given in section 6 .

\section{The Black Forest storm of $\mathbf{1 5}$ July $\mathbf{2 0 0 7}$}

On 15 July 2007, the COPS area was located in the transition zone between an eastern European ridge, stretching from the Mediterranean Sea to Poland, and a high-amplitude eastern Atlantic trough. The associated large-scale forcing was very weak (Kottmeier et al., 2008). The different soundings performed in the COPS area exhibited only moderate values of convective available potential energy and relatively high values of convective inhibition (Kalthoff et al., 2009; Barthlott et al., 2010). Under such conditions, convection triggering was unlikely. However, a line of convective clouds reaching up to a height of $12 \mathrm{~km}$ developed over the Black Forest during the mid-afternoon. The first sign of convective development appeared on the satellite images of 1200 UTC, first on the southern part of the Black Forest and then on both northern and southern parts of the massif (see Figure 1 at 1215 UTC). At 1300 UTC the cloud pattern evolved into a line oriented south-north and roughly $80 \mathrm{~km}$ long, which started to dissipate after 1500 UTC.

This storm was well observed with several radars of the COPS area including the research polarimetric radar POLDIRAD, set up close to Strasbourg in the Rhine valley. Figure 2 shows a time sequence of Plan Position Indicator (PPI) scans taken every 20 minutes between 1420 and 1520 UTC. These pictures indicate that mostly the southern part of the cloud system was associated with deep convection and significant precipitation. A Range Height Indicator (RHI) scan performed across the storm at 1444 UTC (see Figure 3) exhibits high reflectivity values exceeding $60 \mathrm{dBZ}$ and a cloud top reaching $12 \mathrm{~km}$ in height. 

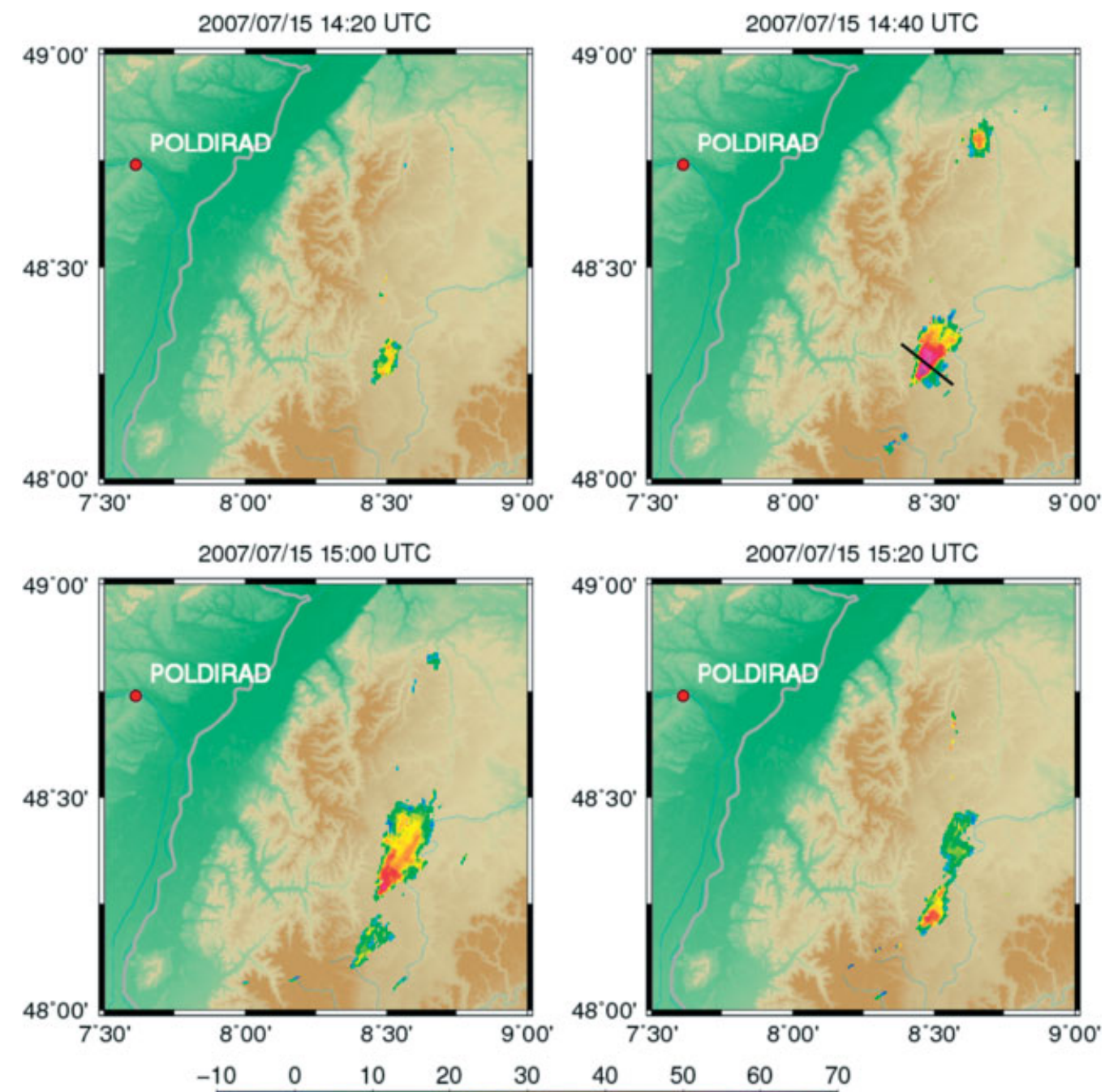

reflectivity [dBZ]

Figure 2. Time evolution of the reflectivity measured with Poldirad: PPI scan at $2^{\circ}$ elevation between 1420 UTC and 1520 UTC. The black line indicates the location of the vertical cross-section shown in Figure 3.

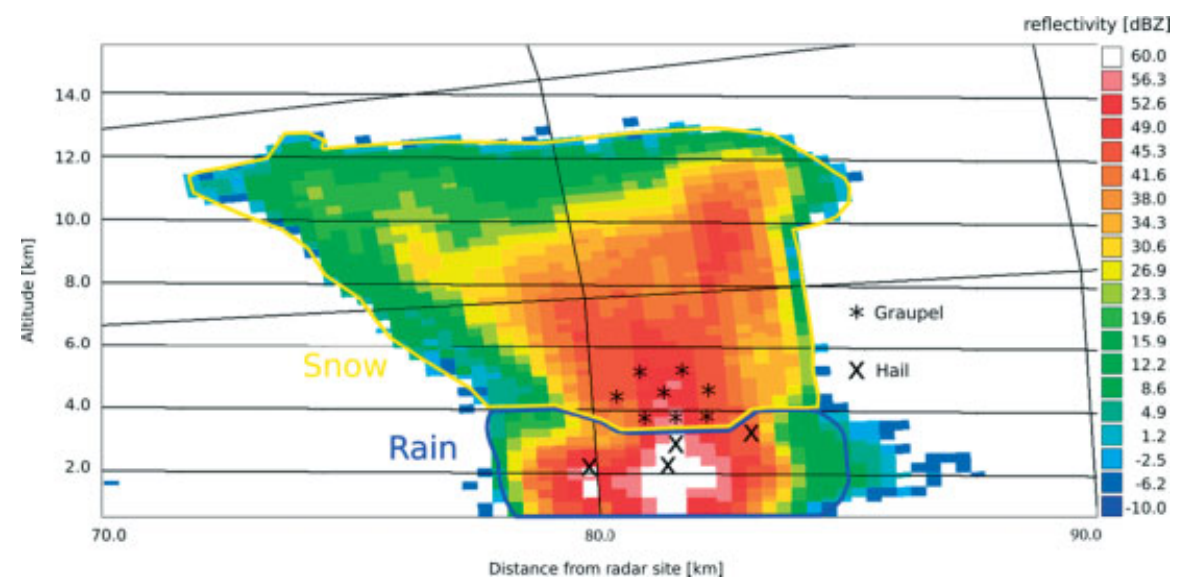

Figure 3. Vertical cross-section of the reflectivity measured with Poldirad: RHI scan performed at 1444 UTC with $130^{\circ}$ azimuth. The yellow and blue contours delineate the areas in which the dominant types of hydrometeors are snow and rain, respectively. Graupel and hail are found in the areas marked with stars and crosses, respectively.

Further information on the storm microphysics was obtained using the cloud hydrometeor classification of Höller et al. (1994). According to this classification, hail is present if the differential reflectivity (ZDR) ranges between +1 and $-1 \mathrm{~dB}$ and the linear depolarization ratio (LDR) is between -25 and $-15 \mathrm{~dB}$. In the area of high reflectivity over
$50 \mathrm{dBZ}$, these conditions were met around a height of $3 \mathrm{~km}$ in a small region. However, in the next southerly cross-section (performed at $132^{\circ} 20 \mathrm{~s}$ later, not shown) a more significant hail area was found, reaching down to $1 \mathrm{~km}$ height. An alternative method to identify hail with a polarized radar is based upon the use of the hail differential reflectivity 
(HDR: Aydin et al., 1986), a function of the reflectivity and the differential reflectivity only. In the vertical cross-section shown in Figure 3 the HDR reaches values up to $32 \mathrm{dBZ}$, which is consistent with the results of Höller's method for hail occurrences (Depue et al., 2007).

\section{Model set-up and experimental design}

The numerical simulations were performed with the French non-hydrostatic mesoscale model Meso-NH (Lafore et al., 1998), jointly developed at Météo-France and at the Centre National de la Recherche Scientifique. The model solves a non-hydrostatic system of equations based upon the Durran (1989) anelastic formulation. A C-grid in the formulation of Arakawa (Mesinger and Arakawa, 1976) is used for the spatial discretization and the temporal scheme is an explicit leap-frog scheme with a time filter (Asselin, 1972). The model prognostic variables are the three-dimensional wind components, the potential temperature, the turbulent kinetic energy and the mixing ratios of water vapour and six classes of hydrometeors. A bulk microphysical scheme (Pinty and Jabouille, 1998; Lascaux et al., 2006) governs the equations of seven water species (vapour, cloud water, rainwater, pristine ice, snow, graupel and hail). The turbulence parametrization is based on a 1.5-order closure (Cuxart et al., 2000) and the surface scheme Interactions between Soil, Biosphere and Atmosphere (ISBA) is described in Noilhan and Planton (1989).

During the COPS field experiment, Meso-NH was run in real time on three interactively two-way nested domains (Stein et al., 2000) with horizontal mesh sizes of 32, 8 and $2 \mathrm{~km}$. The area corresponding to the coarsest domain (D1) is shown in Figure 4(a), together with the location of the nested domains (D2 and D3). D1 covers the synoptic conditions above western Europe, D2 corresponds to the MAP-D-PHASE domain and D3 is centred above the COPS area. The topography of the innermost domain is shown in Figure 4(b). The convection scheme of Kain and Fritsch (1993) adapted to the Meso-NH model by Bechtold et al. (2001) was activated for the coarser grids, while convection was assumed to be explicitly resolved for the $2 \mathrm{~km}$ grid. The initial conditions were obtained from the European Center for Medium-range Weather Forecasts (ECMWF) analysis of 15 July at 0000 UTC and the boundary conditions for the outermost domain were interpolated in time from the six-hourly ECMWF forecasts. The control run presented in this study (referred to as ECMCTL) is identical to the run performed in real time except that it was obtained with a more recent version of the model which, in particular, includes a better advection scheme for moisture (the Multidimensional Positive Definite Advection Transport Algorithm (MPDATA) instead of the standard Flux Corrected Transport scheme (FCT)). Compared with the real-time simulation used in Barthlott et al. (2011), this change may have affected the results, but only in certain details.

\section{Model results}

As already mentioned, the Meso- $\mathrm{NH}$ forecast of the 15 July storm was quite satisfactory. Figure 5 allows the model results to be assessed in terms of satellite and radar pseudoobservations. The top panels show the time evolution of the $280 \mathrm{~K}$ contour of the brightness temperature as measured in the METEOSAT $10.8 \mu \mathrm{m}$ channel (Figure 5(a)) and as derived from the model fields (Figure 5(b)) following the model-to-satellite approach of Chaboureau et al. (2000). The evolution of the $280 \mathrm{~K}$ contour allows the convective activity to be monitored. Model results are in fairly good agreement with the observations. Convection is triggered around 1300 UTC and only lasts for a couple of hours. The triggering occurs over the southern Black Forest on its northeastern slope $\left(48^{\circ} \mathrm{N}, 8.35^{\circ} \mathrm{E}\right)$ and the storm propagates towards the northeast. The main departure from the observations is a slightly slower propagation and thus a slightly shorter trajectory of the storm. These results also indicate that the spatial extent of the cloud anvil appears underestimated in the simulation. This could be linked to some deficiency in the microphysical scheme (e.g. a too-active ice-to-snow conversion process as suggested by Chaboureau et al., 2002). However, this effect might also be artificially amplified due to the parallax error of the satellite observations (Johnson et al., 1994). Taking into account the cloud-top height and the METEOSAT position with respect to the COPS area, the observations may present a northward displacement error of $10-20 \mathrm{~km}$, which can explain, at least partially, the discrepancy between the observations and the model results.

The bottom panels of Figure 5 focus on the precipitating parts of the convective system. Figure 5(c) shows the time evolution of the $10 \mathrm{dBZ}$ reflectivity contour measured by the Feldberg radar every 15 min during its $1.5^{\circ}$ elevation scan. At the location of the storm, this corresponds roughly to $3000 \mathrm{~m}$ above sea level. The same contour of the simulated reflectivity at $3000 \mathrm{~m}$ is represented in Figure $5(\mathrm{~d})$. The agreement between the observations and the simulation is remarkable. Initiation time, duration and trajectory of storm are quite well captured by the model.

Further assessment of the forecast can be achieved by comparing the vertical structure of the simulated cloud system with the observed one. Figure 6 shows the computed radar reflectivity superimposed with the snow, graupel, hail and rain mixing ratios in a vertical cross-section located along the POLDIRAD line of sight $\left(130^{\circ}\right)$. This figure can be directly compared with the observations shown in Figure 3 , except that it is shifted southward by $5 \mathrm{~km}$ to intercept the most active part of the model storm. The cloud depth $(12 \mathrm{~km})$ and the reflectivity intensity (reaching $59 \mathrm{dBZ}$ ) are well-captured. However, the model storm appears wider than the observed one and it is likely that the $2 \mathrm{~km}$ grid spacing of the model is insufficient for a more accurate description. Another point of discrepancy between model results and observations is an underestimation of the reflectivity below freezing level, which could result from too fast a melting of graupel and hail particles. As stressed by Phillips et al. (2007), this process is inaccurately represented in one-moment bulk schemes. According to the model, and consistent with the observations, the anvil composed of snow aggregates spreads towards the northwest whereas, at $3 \mathrm{~km}$ height, the precipitation is carried by a mixture of hail particles and raindrops.

Taking into account the small likelihood for convective development on this particular day as well as the great difficulty of accurately predicting isolated storms, the Meso$\mathrm{NH}$ forecast can be considered as very successful. This feeling was corroborated by the fact that, among the various models running for that day in the framework of the MAP-DPHASE project, only two out of twelve were able to capture the event. Additional studies carried out a posteriori and 
(a)

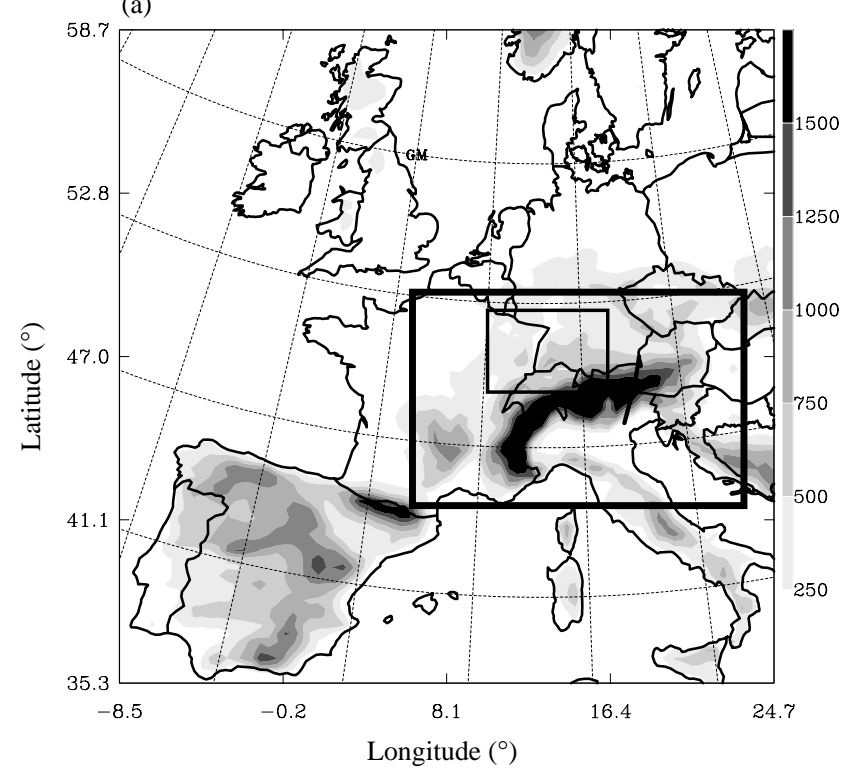

(b)

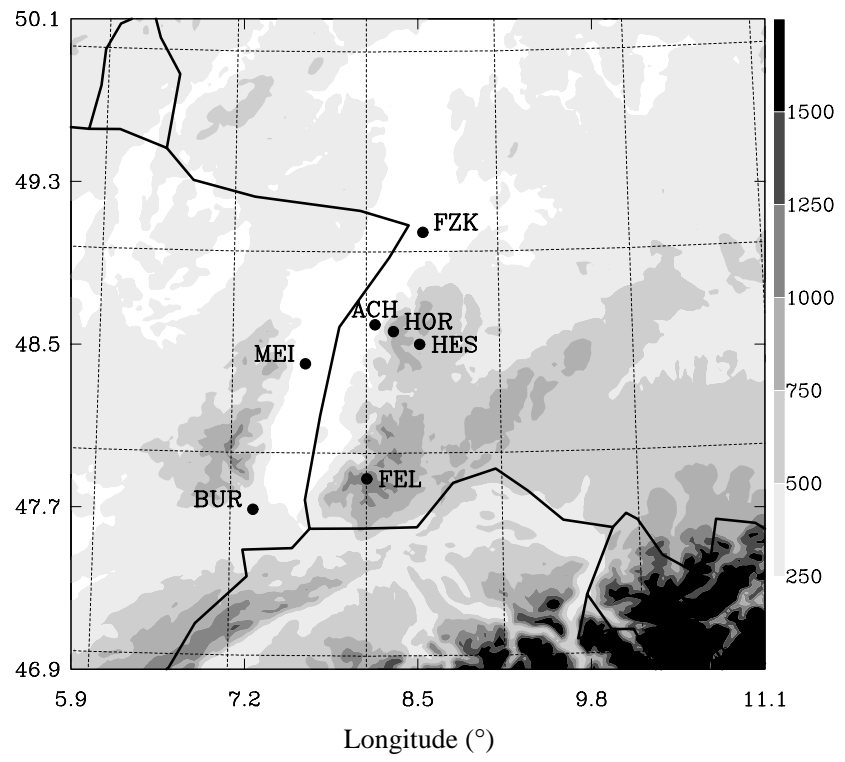

Figure 4. (a) Geographical domains used for the nested simulation. The outer frame shows the $32 \mathrm{~km}$ grid-mesh domain and its topography; the location of the $8 \mathrm{~km}(2 \mathrm{~km})$ grid-mesh domain is indicated with a thick- (thin-) lined square. (b) Topography (in $\mathrm{m}$ ) of the $2 \mathrm{~km}$ grid-mesh domain and locations of instrumented sites: Forschungszentrum Karlsruhe (FZK), Hornisgrinde (HOR), Achern (ACH), Heselbach (HES), Meistratzheim (MEI), Burnhaupt (BUR) and Feldberg (FEL).

using various model set-ups have confirmed the difficulty of obtaining a good forecast of the observed storm (Barthlott et al., 2011). In the following, we will concentrate on the model evaluation, looking at the various elements that lead to convective development, and we will try to analyze whether this good forecast was obtained for the right reasons.

\section{Triggering factors}

The triggering of convection essentially depends on three parameters: the potential instability of the air mass, the moisture supply in the low levels of the atmosphere and a $\beta$-mesoscale vertical ascending motion resulting (in the absence of large-scale forcing) from either orographic lifting and/or diurnal thermal heating of the ground. In the next subsections, we examine how and in what proportions these different factors are present in the simulation and how well they compare with the available observations.

\subsection{Potential instability}

Six soundings with roughly three-hourly ascents are available to assess the stability conditions. Four of them are located in the plain along the Rhine river and three of them in the Black Forest area, but unfortunately $60 \mathrm{~km}$ north of the storm development (see Figure 4(b) for the sounding locations). As stressed in Kalthoff et al. (2009), the different indexes traditionally used to quantify the atmospheric instability do not show very propitious conditions for convection. The Convective Available Potential Energy (CAPE) barely reaches $1200 \mathrm{~J} \mathrm{~kg}^{-1}$, whereas the Convective Inhibition (CIN) remains significant except over the mountains. Figure 7 shows the CAPE and CIN computed from the model fields and superimposed with the values deduced from the soundings after their interpolation on the vertical grid of the model. The computations follow Emanuel (1994) and are performed from each model level. The CAPE and CIN values are selected as the values obtained for the lifting model level leading to the maximum of CAPE (usually, but not systematically, the closest level to the ground). According to the model, at 1100 UTC the CAPE is stronger over Germany than over France. Three hours later, the CAPE has significantly increased over the mountainous areas but remains stronger over the Black Forest, reaching $3000 \mathrm{~J} \mathrm{~kg}^{-1}$ in two places: one over the western slope of the southern Black Forest (corresponding to the steepest orography of the domain) and a second, less intense but spatially wider, over the area where the convection is triggered. From the model results, high CAPE appears to be a necessary but not sufficient condition to explain the location of the convective development. In comparison with the observation the modelled CIN is underestimated in the morning, but this is no longer the case in the early afternoon except in Burnhaupt. Otherwise, there is no major inconsistency between model results and observations, but unfortunately no soundings are located sufficiently close to the area of interest.

\subsection{Moisture supply}

A real achievement of the COPS experiment is a fairly exhaustive documentation of the water-vapour field, which was sampled by several in situ and remote, ground-based and airborne instruments (Bhawar et al., 2011). This very dense and unique data set is used below to assess the validity of the model results further. Compared with the wide coverage provided by the airborne lidar observations, the local soundings give only a very partial picture of the spatial distribution, but they are classically used as a reference for moisture measurements. Therefore, model results are first compared with the available soundings. Figure 8 shows the time evolution of the moisture vertical profiles, observed and modelled, between 0600 and 1700 UTC and from Karlsruhe in the north to Burnhaupt in the south. In general, model profiles tend to present a moist bias. This bias is weak in the morning but reaches up to $2 \mathrm{~g} \mathrm{~kg}^{-1}$ in the mid-afternoon 

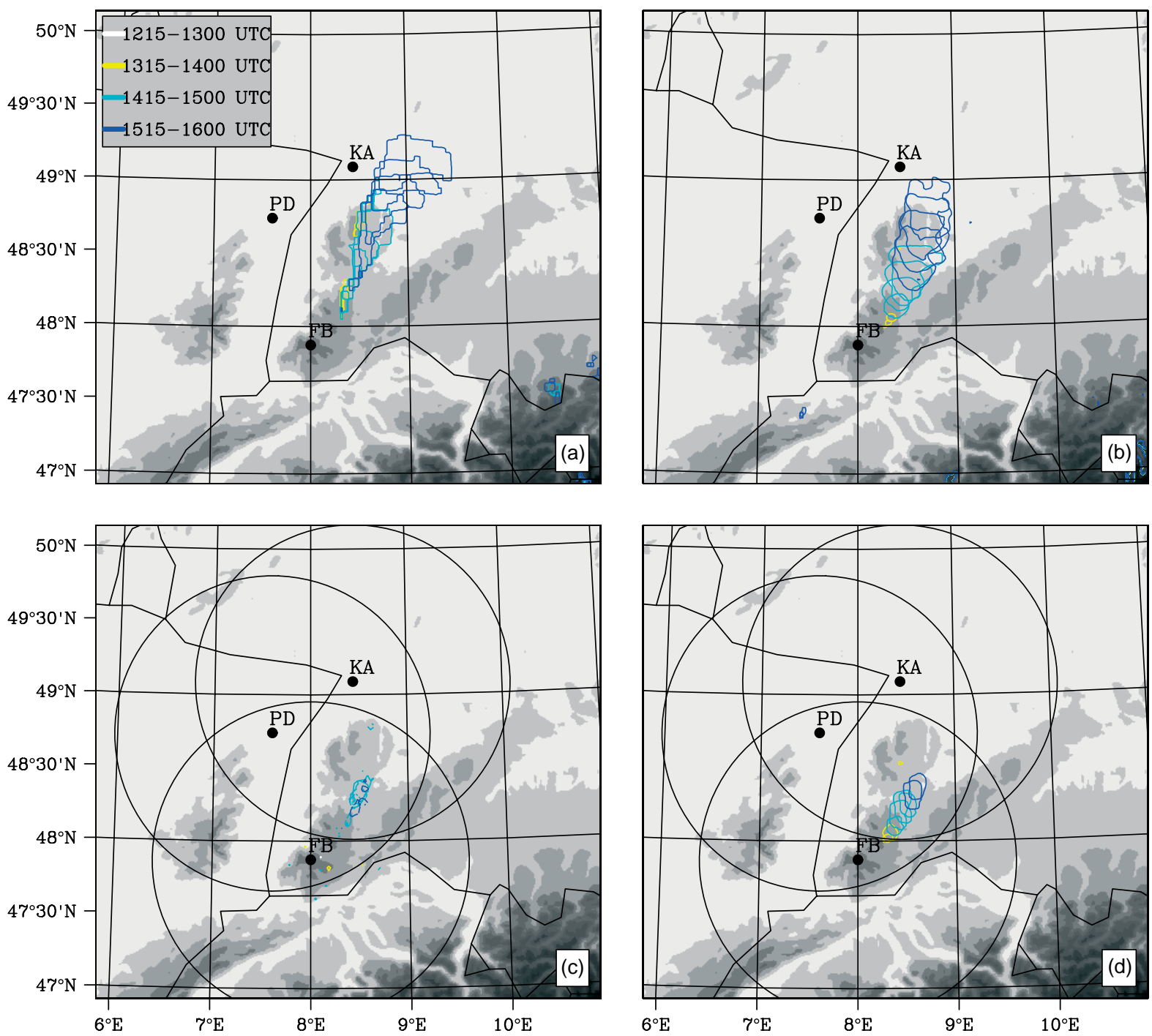

Figure 5. Time evolution of the 15 July 2007 storm between 1200 UTC and 1600 UTC: (a) $280 \mathrm{~K}$ contour of the brightness temperature observed with METEOSAT8 in the $10.8 \mu \mathrm{m}$ channel; (b) same as (a) but simulated with Meso-NH; (c) $10 \mathrm{dBz}$ contour of the reflectivity measured by the Feldberg radar $\left(1.5^{\circ}\right.$ elevation scan) and (d) same as (c) but simulated with Meso-NH at $3 \mathrm{~km}$ height. Contours are plotted every 15 min with a different colour every hour. The symbols KA, PD and FB indicate the location of the Karlsruhe, Poldirad and Feldberg radars respectively. The black circles mark the $120 \mathrm{~km}$ range of each radar.

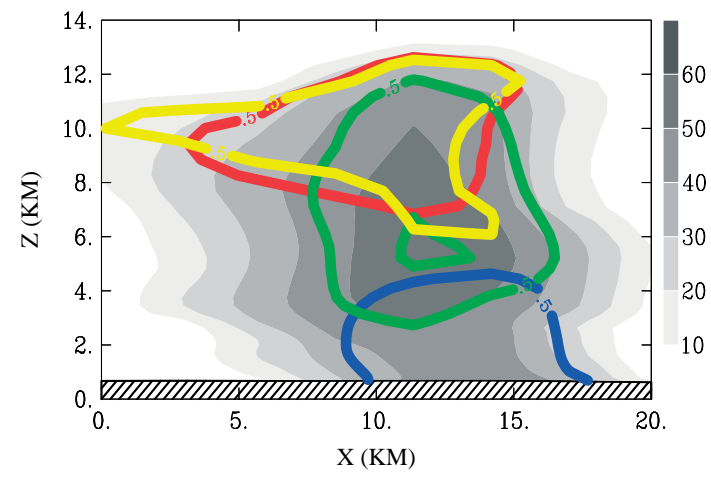

Figure 6. Vertical cross-section of the simulated cloud at 1445 UTC: reflectivity field (grey shading), snow (yellow), graupel (red), hail (green) and rain (blue) mixing ratios $\left(0.5 \mathrm{~g} \mathrm{~kg}^{-1}\right.$ contour interval). The location of the section corresponds to the one shown in Figure 3 except that it is shifted southward by $5 \mathrm{~km}$.

and is particularly large between the heights of 1 and $3 \mathrm{~km}$. For this altitude range, it can be seen that the bias is well marked at 1100 UTC in the south of the domain (BUR) but only at 1700 UTC in the north of the domain (FZK), indicating that it results from too slow an advection of the dry air entering the domain from the northwest. Regarding the boundary-layer behaviour and the first kilometre above ground, the model results seem correct except for HOR, HES and BUR after 1400 UTC, where some significant positive bias can also be noted. For this lower level, the bias is more probably related to some surface and/or boundary-layer parametrization issues.

Several past studies have questioned the accuracy of moisture measurements provided by radiosondes and reported on the necessity of different bias corrections depending on the type of sondes (Agusti-Panareda et al., 2009, and references herein). Most of the soundings performed on 15 July used Vaisala RS92 sondes, which are considered as very accurate in the low troposphere. It is therefore unlikely that the moist bias of the model could result from a dry bias of the sondes. Furthermore, the model bias is confirmed by using another source of moisture observations. Figure 9 shows the time evolution of the vertical moisture profile simulated above Achern and observed with the Raman lidar system BASIL from 
11:00 UTC
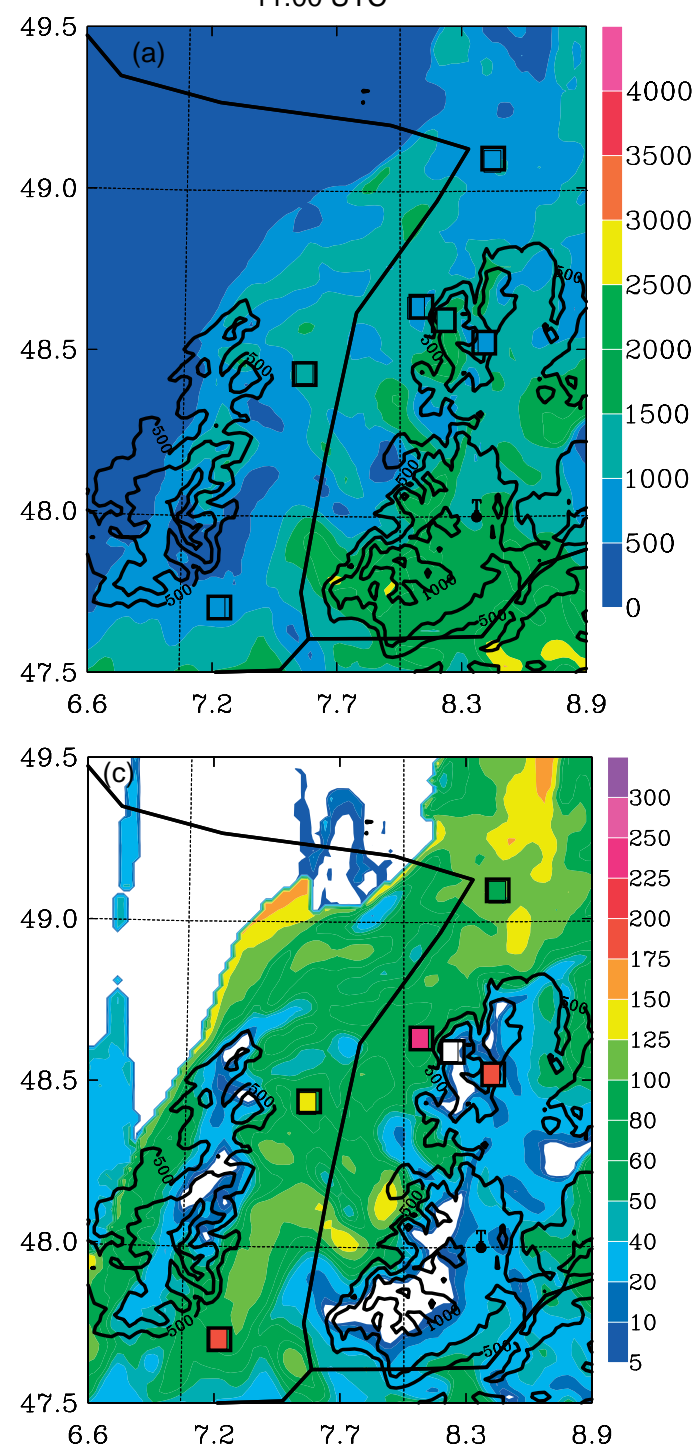

14:00 UTC
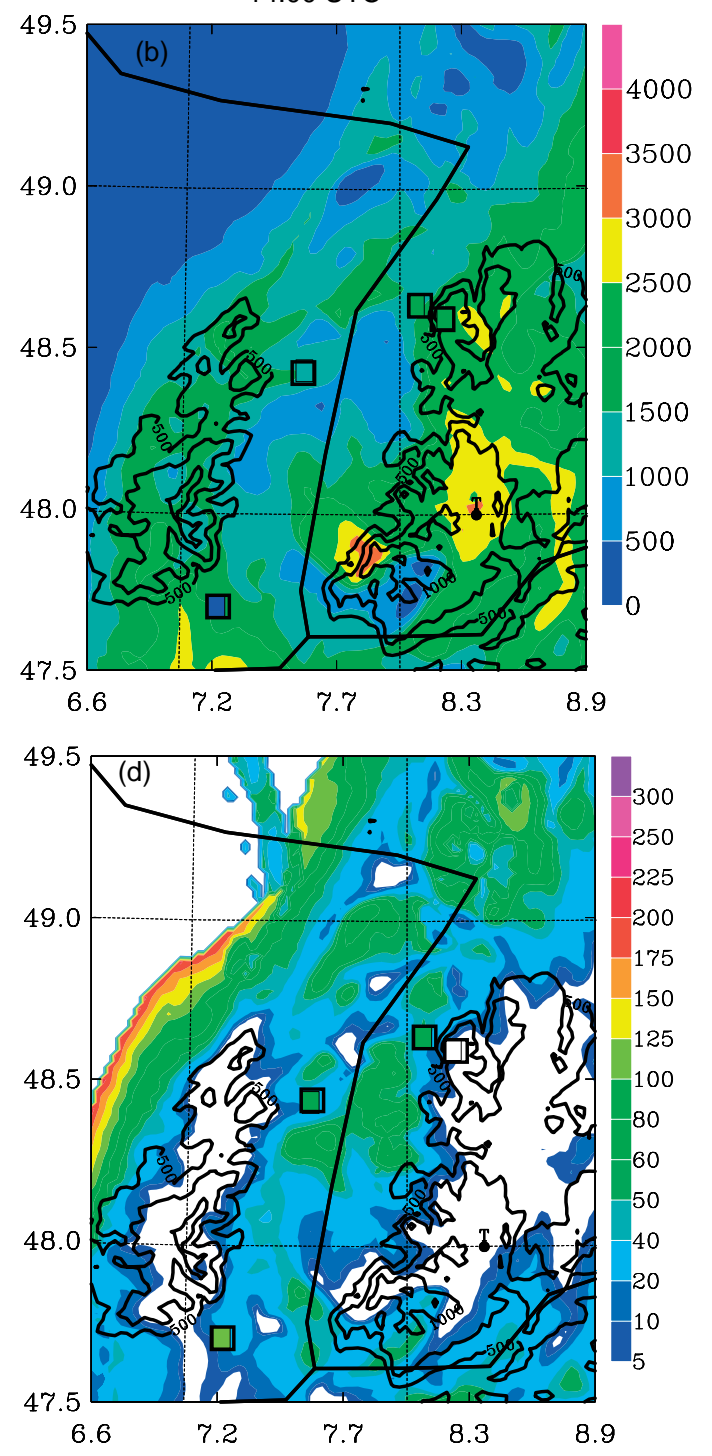

Figure 7. CAPE (top) and CIN (bottom) in $\mathrm{Jg}^{-1}$ at $1100 \mathrm{UTC}$ (left) and $1400 \mathrm{UTC}$ (right) as simulated by Meso-NH. The CAPE and CIN values deduced from the available soundings are reported within the coloured squares. The black isolines correspond to the model topography (500, 750 and $1000 \mathrm{~m}$ contours).

the University of Basilicata (Di Girolamo et al., 2009a,b). Without reproducing the detailed structure of the field, the model depicts the diurnal deepening of the planetary boundary layer reasonably well. However, it is also clear from this other set of observations that the model is too moist by roughly $2 \mathrm{~g} \mathrm{~kg}^{-1}$ in the $1-3 \mathrm{~km}$ height range. A very similar result (not shown; V. Wulfmeyer and A. Behrendt, private communication) was obtained when the comparison was made with the DIAL lidar system of the University of Hohenheim, which was located in Hornisgrinde (Behrendt et al., 2011).

A better description of the moisture spatial distribution is obtained by analyzing and combining various airborne moisture observations: in situ measurements performed by the Dornier 28 and airborne lidar measurements provided by the LEANDRE II system (Bruneau et al., 2001) on board the Service des Avions Français Instrumentés pour la Recherche en Environnement (SAFIRE) Falcon and from the WAter vapour Lidar Expriment in Space (WALES) system on board the DLR Falcon. The three aircraft flew in the morning (the SAFIRE Falcon between 0630 and 1000 UTC, the DLR
Falcon between 0700 and 1000 UTC and the Dornier 28 between 0600 and 0915 UTC). In the afternoon, only the SAFIRE Falcon and the Dornier operated (between 1130 and 1500 and between 1140 and 1500 UTC respectively). Figure 10 shows the time evolution of the horizontal moisture field from the morning to the afternoon and for heights of 2000 and $1000 \mathrm{~m}$. The different observations are superimposed on the model fields and are marked with squares. To focus on the spatial structure, the model bias was removed by subtracting a constant value of $2 \mathrm{~g} \mathrm{~kg}^{-1}$ from the model fields. In the morning, the model fields are fairly homogeneous except for the lowest level, where the southeastern part of the domain appears comparatively moister. These results are consistent with the observations. In the early afternoon, some more distinct patterns show up. Very dry air is entering the domain from the northwest, first at high level then at low level. The Rhine valley remains drier than the surrounding mountains, above which moisture seems to concentrate. At $2 \mathrm{~km}$ height, the Dornier measurements show a very sharp gradient of the moisture field above the northern Black Forest. Model results reproduce all these features well but 

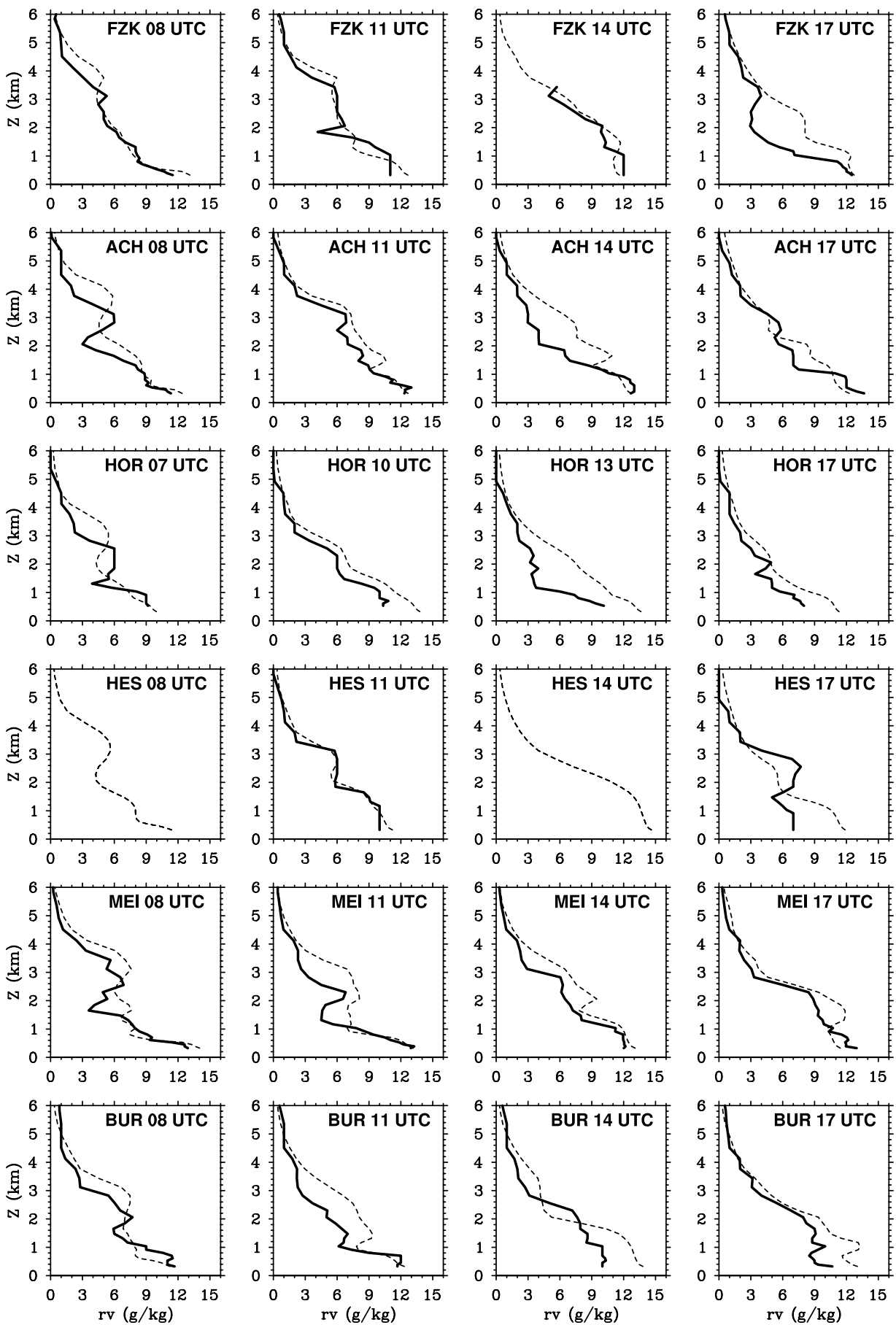

Figure 8. Time evolution of the moisture vertical profiles, simulated (dashed) and measured with radiosondes (solid), in Forschungszentrum Karlsruhe (FZK), Achern (ACH), Hornisgrinde (HOR), Heselbach (HES), Meistratzheim (MEI) and Burnhaupt (BUR).

tend to overamplify the moisture accumulation over the mountain crests. For instance, over the Vosges summits the observations are 1 or $2 \mathrm{~g} \mathrm{~kg}^{-1}$ moister than over the Rhine Valley, whereas the model predicts a $2-3 \mathrm{~g} \mathrm{~kg}^{-1}$ moisture excess.

\subsection{Vertical motion}

Considering the weakly unstable conditions, vertical motion had to be significant to trigger convection. Kalthoff et al. (2009) suggest that a synoptically induced mesoscale convergence line, propagating eastwards, was strongly reinforced by the thermally driven circulation that developed along the northern crest of the Black Forest and provided the uplift necessary to overcome the CIN over the Hornisgrinde mountain. More in the south, another convergence line oriented southwest-northeast developed in the lee of the Feldberg as early as 1100 UTC and slowly propagated eastwards. The time evolution of this latter convergence line is examined by Barthlott et al. (2010) using the Doppler velocity field measured by the Feldberg DWD radar.

As can be seen in Figure 11, these two features are fairly well reproduced by the model. Although there is no evidence of a pre-existing mesoscale convergence line in the northern part of the domain, the model captures the occurrence and the time and space evolution of the two observed convergence lines very well. In the model, vertical 
Observation - Basil lidar

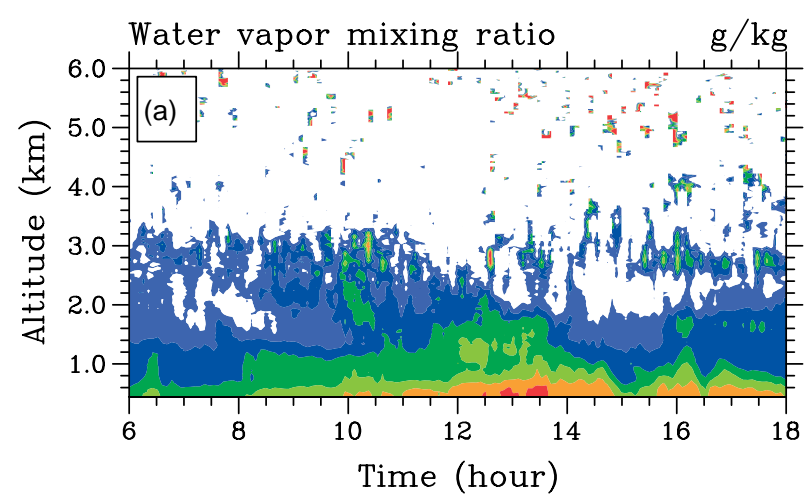

Simulation - ECMCTL

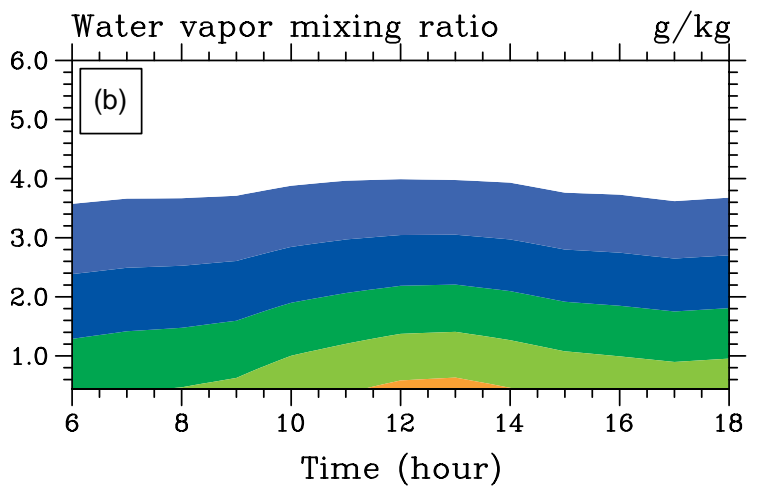

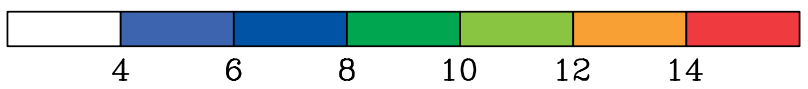

Figure 9. Time evolution of the moisture vertical profile in Achern: (a) observations from the Raman lidar system BASIL; (b) Meso-NH simulation. This figure is available in colour online at wileyonlinelibrary.com/journal/qj
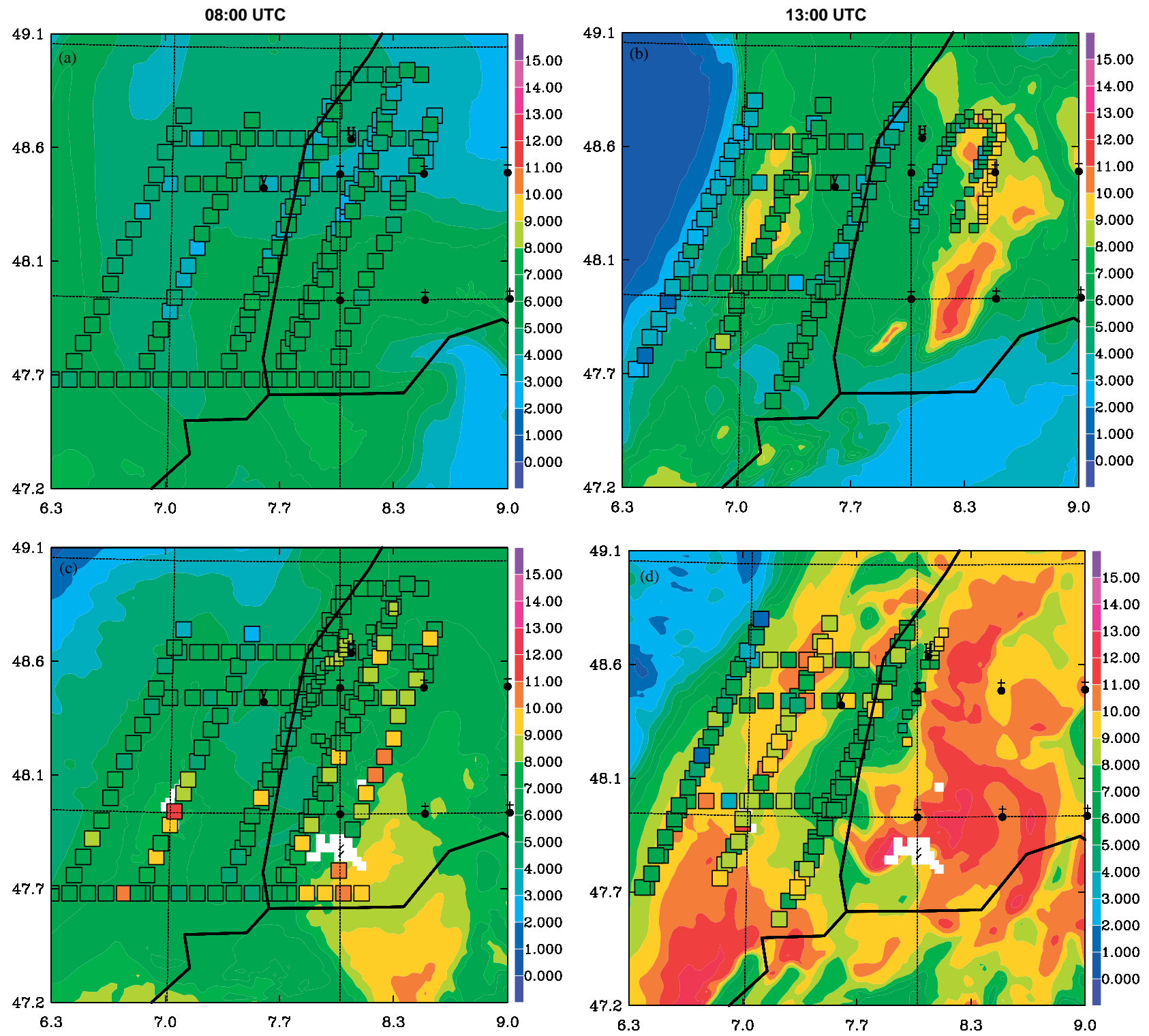

Figure 10. Horizontal cross-sections of the simulated water-vapour mixing ratios superimposed with the available observations (coloured squares) at $2000 \mathrm{~m}$ ASL (top) and $1000 \mathrm{~m}$ ASL (bottom) and at 0800 UTC (left) and 1300 UTC (right). The bigger squares correspond to the WALES and LEANDRE observations whereas the smaller squares are related to the Dornier in situ measurements. Model values have been uniformly reduced by $2 \mathrm{gkg} \mathrm{k}^{-1}$ to remove the bias. 
(a) 10:00 UTC

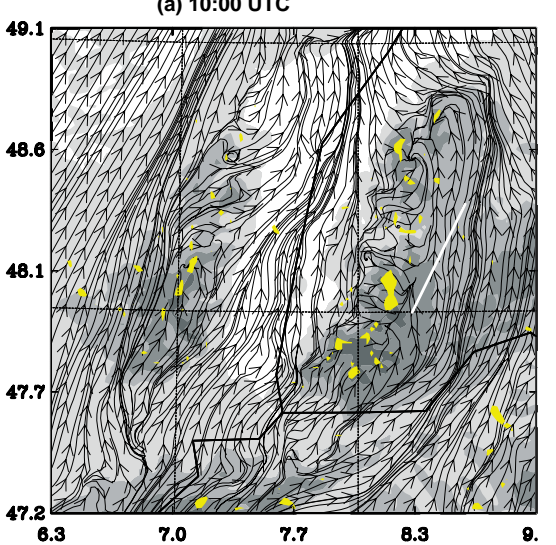

(b) 12:00 UTC

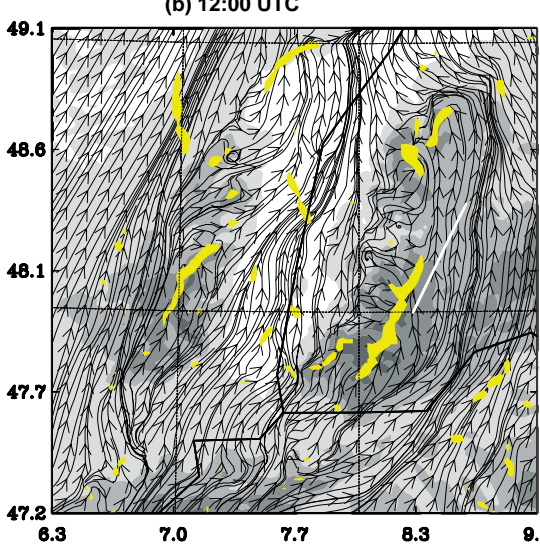

(c) 14:00 UTC

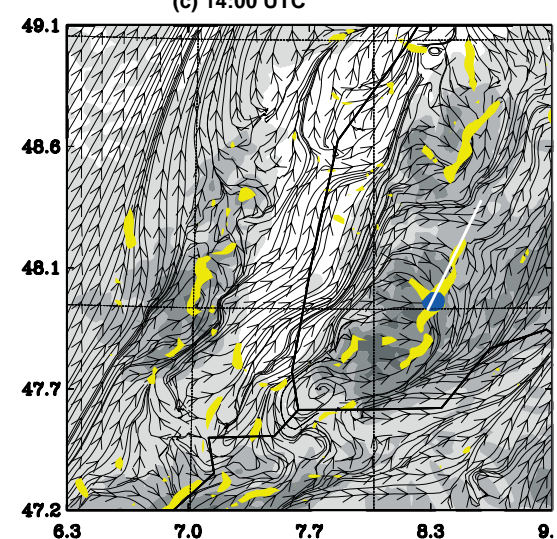

Figure 11. Streamlines and convergence in excess of $0.5 \times 10^{-3} \mathrm{~s}^{-1}$ at $1200 \mathrm{~m} \mathrm{ASL}$. The white line indicates the trajectory of the storm and the blue spot the location of the first convective developments.

motion first occurs over the mountain crests in response to the thermal heating and is then reinforced by leeside convergence effects. More precisely, in the morning the lowlevel flow is more or less channelled in the Rhine valley. In the afternoon, following the synoptic evolution, the flow slowly rotates eastward, impinges the Black Forest, splits around the main peaks and converges in the lee of Hornisgrinde and also more clearly in the lee of the Feldberg, where the first major convective developments take place.

\subsection{Discussion}

In view of the various parameters examined above, the simulation results are very realistic and the model errors are, in general, found to be small. As shown in Barthlott et al. (2011), a moist bias is present in most of the simulations carried out for this event but the bias obtained with Meso$\mathrm{NH}$ is among the largest. It is therefore important to investigate further which parameters controlled the moisture vertical distribution in the model. Moreover the Meso-NH errors are such that they probably favoured the development of the storm. In particular, the low-level moist bias of the model accompanied by a small low-level cold bias in the temperature (not shown yet) could act to increase the CAPE and reduce the CIN. Another point of uncertainty is the strength of the vertical motion prior to convection. The comparison with the Feldberg radar data clearly proves that the convergence line develops at the right location and evolves correctly with time, but it does not provide true quantitative information on the uplift intensity. At this point, therefore, we cannot exclude the possibility that the forecast is good mainly by chance and thanks to the combination of small but synergistic errors. This is why the case was further investigated by performing various sensitivity tests aimed at assessing the robustness of the results.

\section{Sensitivity experiments}

\subsection{Sensitivity to initial and forcing conditions}

First, a twin experiment (referred to as ARPCTL) was carried out in exactly the same conditions except that the initial fields (boundary conditions) were obtained from the Action de Recherche Petite Echelle Grande Echelle (ARPEGE) analysis (forecast) instead of the ECMWF analysis (forecast). Surprisingly, the latter experiment produced even more (and actually too much) convection than the ECMWF-based experiment. Figures 12(a) and 13(a) use the same display as Figure 5(b) and (d), respectively, and summarize the evolution of the convective activity in terms of brightness temperature and radar reflectivity. The southern Black Forest storm develops at approximately the same location and is well captured. The secondary cell occurring in the northern Black Forest (missed by ECMCTL) is also well captured although slightly overpredicted. However, ARPCTL produces convection in several places where it was not observed (e.g. over the Vosges or in the northeastern section of the domain).

To discriminate between the impact of initial conditions and the impact of boundary conditions, an additional experiment was carried out using ECMWF analyses as initial fields and ARPEGE forecasts as boundary conditions. Not unexpectedly, given the large outer model domain, the results were very similar to the results of the control experiment, which led us to focus on the initial conditions. Careful inspection of the different initial fields revealed several major discrepancies. The ARPEGE analysis was found to be colder ( $1-3 \mathrm{~K}$ in the first $100 \mathrm{~m}$ above ground) in general and also significantly moister over the Vosges region (up to $5 \mathrm{~g} \mathrm{~kg}^{-1}$ in the first $3 \mathrm{~km}$ ) and, but to a lesser extent, over the northeastern part of the domain $\left(\mathrm{g} \mathrm{kg}^{-1}\right.$ within the 1000-2000 m layer). Such differences can probably explain why in ARPCTL convection takes place in the latter regions but not in ECMCTL.

Another major discrepancy between the two sets of analyses concerns the superficial soil moisture contents. In the ISBA surface parametrization, the soil water is distributed into three reservoirs, $w g 1$ representative of the first $\mathrm{cm}$ of soil, a root-zone layer $w g 2$, the depth of which depends upon vegetation type, and a base-flow layer $w g 3$. Whereas $w g 2$ and $w g 3$ are pretty much the same in both experiments, $w g 1$ is much higher in the ECMWF-based experiment than in the ARPEGE-based experiment as illustrated in Figure 14(a) and (b). During the whole COPS period such a difference was not systematic but sometimes occurred, especially on sunny days. In most assimilation systems, the superficial soil moisture is adjusted to minimize the departure from the surface observations ( $2 \mathrm{~m}$ temperature and moisture). When this is done, the soil-moisture variable becomes more a tunable parameter of the surface scheme than a 

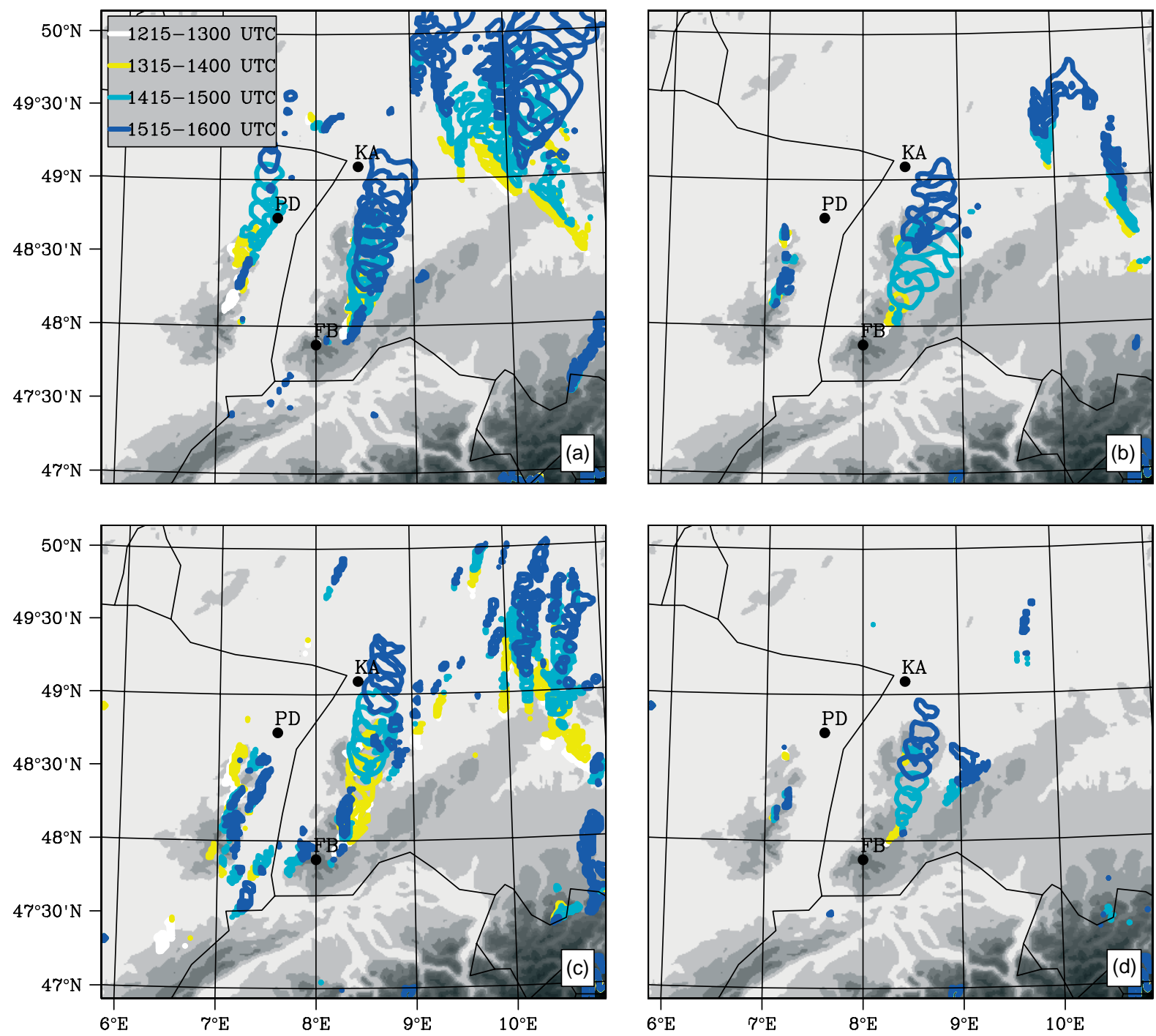

Figure 12. Same as Figure 5(b) but for the various sensitivity experiments: (a) ARPCTL, (b) ECMSM1, (c) ECMSM2 and (d) ECMSM3.

variable representative of a true physical quantity. It would be tempting to compare the two sets of model values with the soil observations, collected during COPS and available at 5,20 and $50 \mathrm{~cm}$ depths. However, it is not straightforward and not even meaningful to transpose the reservoir values into values representative of specific depths. In the absence of further information on the quality of the initial moisture field, we can nevertheless evaluate its influence on our current results by carrying out a new set of experiments, still ECMWF-based but in which the soil moisture of the first reservoir is varied.

\subsection{Sensitivity to the initial surface moisture conditions}

Three additional experiments were performed. In ECMSM1, the ECMWF superficial soil moisture was replaced by the corresponding ARPEGE field, whereas in ECMSM2 and ECMSM3 it was reduced by $20 \%$ and $50 \%$, respectively (see Table I for a list of the various experiments). With a reduction of $20 \%$, the field was still moister than the ARPEGE field whereas a $50 \%$ reduction made it significantly drier, except over the Vosges and also north of the Swabian Jura (see Figure $14(\mathrm{c})$ and $(\mathrm{d}))$.

As expected, when the soil moisture is reduced the planetary boundary layer (PBL) evolution is modified. As
Table I. List of the numerical experiments.

\begin{tabular}{|c|c|c|}
\hline $\begin{array}{l}\text { Experiment } \\
\text { name }\end{array}$ & Initial conditions & $\begin{array}{l}\text { Initial surface } \\
\text { moisture conditions }\end{array}$ \\
\hline ECMCTL & ECMWF & ECMWF \\
\hline ARPCTL & ARPEGE & ARPEGE \\
\hline ECMSM1 & ECMWF & ARPEGE \\
\hline ECMSM2 & ECMWF & $\begin{array}{l}\text { ECMWF } \\
\text { reduced by } 20 \%\end{array}$ \\
\hline ECMSM3 & ECMWF & $\begin{array}{l}\text { ECMWF } \\
\text { reduced by } 80 \%\end{array}$ \\
\hline
\end{tabular}

an example, Figure 15 compares the vertical profiles of the potential temperature and vapour mixing ratios for a few selected soundings (the closest to the storm). Compared with ECMCTL, in all the new experiments except ECMSM3 the cold bias in temperature has almost disappeared and the moisture excess at low levels is significantly reduced. The inspection of all the soundings (not shown) revealed that, in general, ECMSM1 and ECMSM2 gave fairly similar results and also better results than both ECMCTL and ARPCTL. The last experiment, ECMSM3, behaved quite differently. 

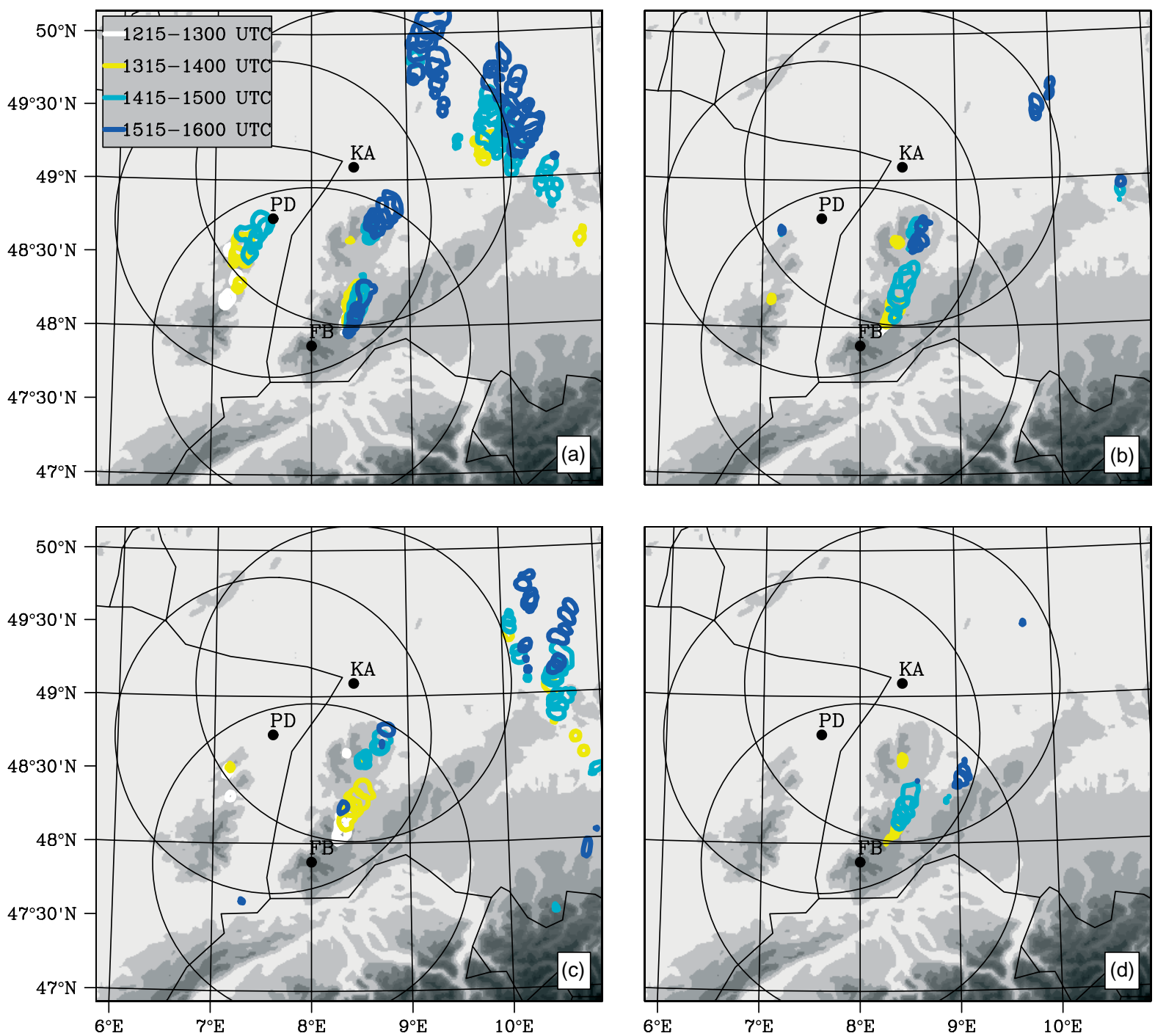

Figure 13. Same as Figure 5(d) but for the various sensitivity experiments: (a) ARPCTL, (b) ECMSM1, (c) ECMSM2 and (d) ECMSM3.

The extremely dry surface conditions propagated in the boundary layer, which was now much deeper, warmer and drier than the observations. The Bowen ratios in the Rhine valley became largely greater than 1 (i.e. values more typical of semi-arid conditions). The results of this experiment are clearly unrealistic.

The positive impact of (reasonably) reduced soil moisture can also be assessed from Figure 16, which, for three vertical west-east cross-sections, compares the model moisture fields of ECMCTL and ECMSM1 with the LEANDRE observations collected during the afternoon flight. The lidar data show the moisture piling up along the eastern slope of the Vosges, and more effectively in the northernmost section. Both simulations reproduce this feature and its north-south gradient, but the results of the sensitivity experiment are now closer to the observations. The results of ECMSM2 are very similar whereas the results of ECMSM3 are far too dry. In the next paragraph, we will examine the extent to which the storm development is affected by the change in surface moisture.

In terms of brightness temperature, ECMSM1 (Figure 12(b)) and ECMSM2 (Figure 12(c)) are close to ARPCTL (Figure 12(a)). Both experiments give reasonable predictions of the northern Black Forest storm but also forecast convection over the Vosges and in the northeast of the domain.
It can be noted that this deficiency is more pronounced in ARPCTL than in ECMSM2, and more in ECMSM2 than in ECMSM1. ECMSM3 (Figure 12(d)) behaves differently: the northern Black Forest storm still occurs but its extent and duration are underestimated whereas almost no convection is forecast either over the Vosges or in the northeast of the domain. Note also that another area of non-observed convection is now found over the Swabian Jura, but it should be remembered that this is one of the rare locations where the surface moisture was still slightly higher than the ARPEGE value. In terms of reflectivity, the three simulations (Figure 13(b)-(d)) reproduce the northern Black Forest storm well, though with a different timing. In particular, ECMSM3 exhibits an earlier development.

The life cycle of the storm can be further assessed in Figure 17, which compares the time evolution of the averaged instantaneous precipitation rate and maximum vertical velocity computed in a box of $40 \mathrm{~km} \times 40 \mathrm{~km}$ centred over the triggering region for all the different simulations. ECMCTL and ARPCTL are roughly similar, with an averaged precipitation rate peaking at $5 \mathrm{~mm} \mathrm{~h}^{-1}$ and maximum vertical velocities exceeding $20 \mathrm{~m} \mathrm{~s}^{-1}$, lasting for at least $2.5 \mathrm{~h}$ (ARPCTL) or $2 \mathrm{~h}$ (ECMCTL). For ECMSM1, the values are in the same range except that the storm has a shorter duration ( $1 \mathrm{~h}$ ). For ECMSM2 and ECMSM3, the 
(a)

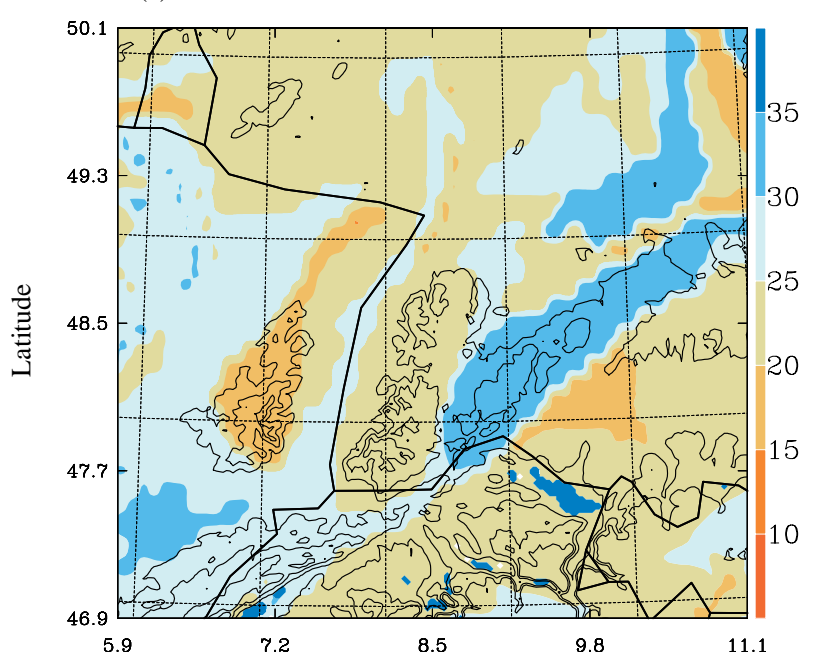

(c)

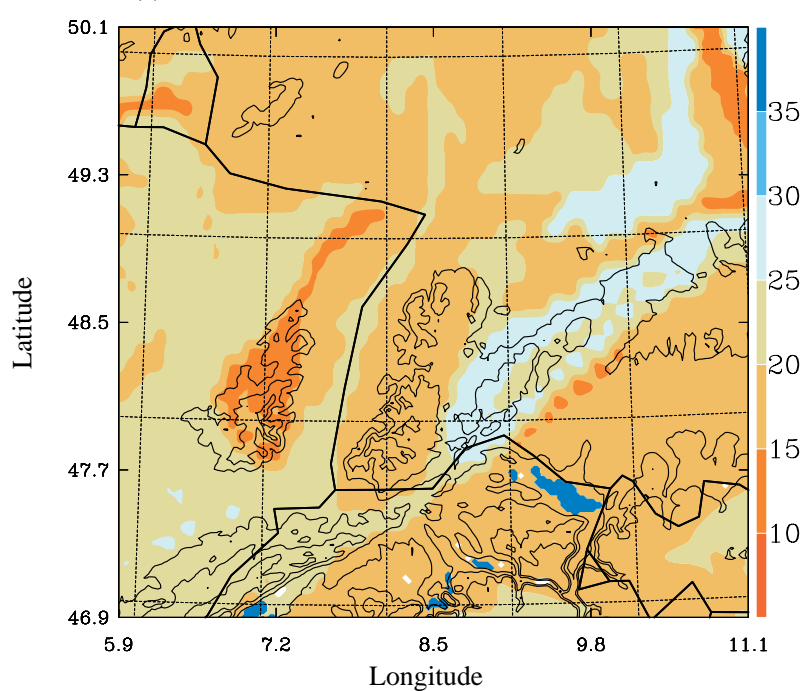

(b)

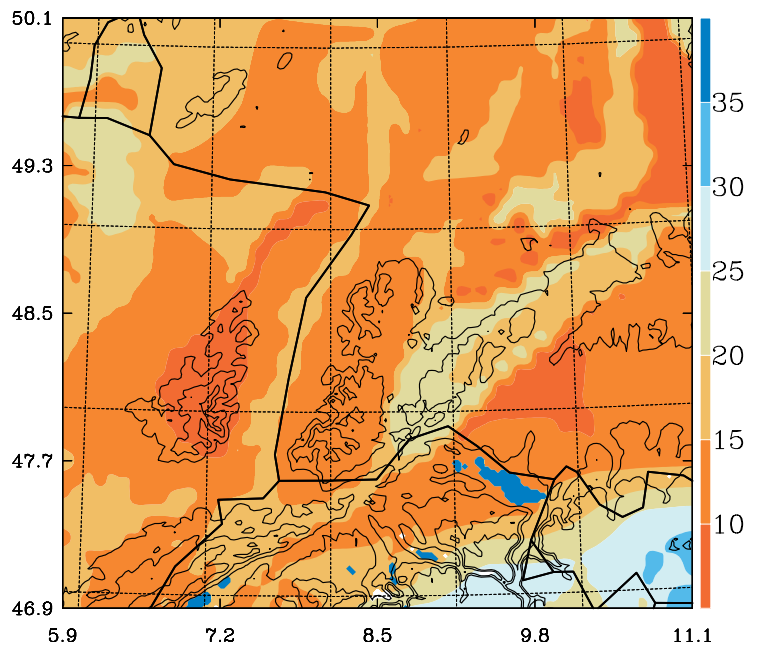

(d)

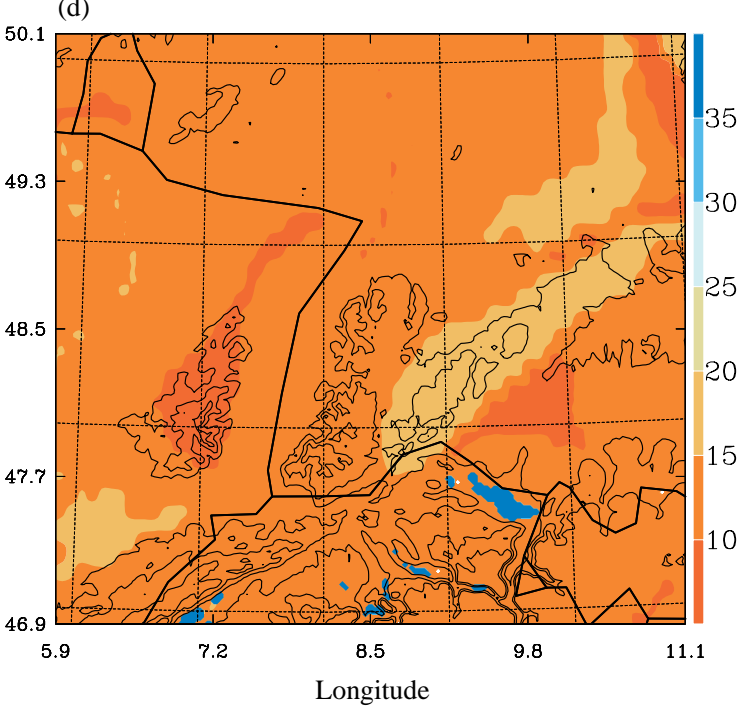

Figure 14. Superficial soil moisture initial conditions (in \%) for (a) ECMCTL, (b) ARPCTL, (c) ECMSM2 and (d) ECMSM3 experiments.
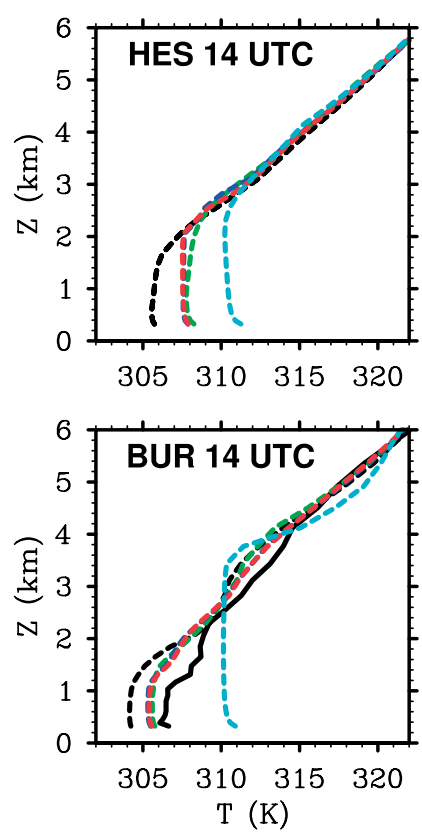
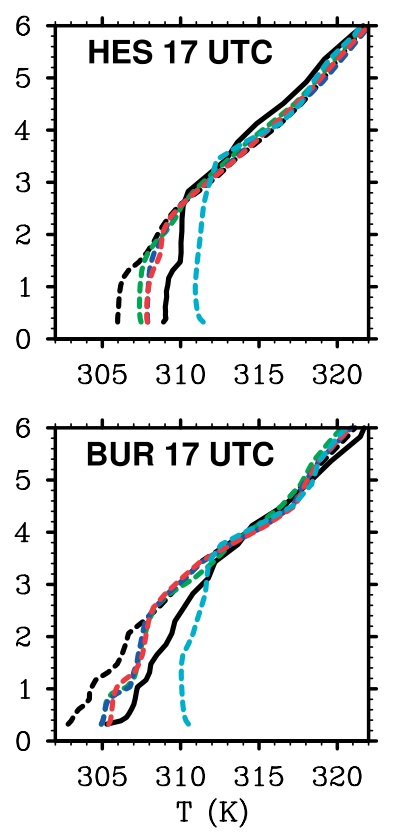
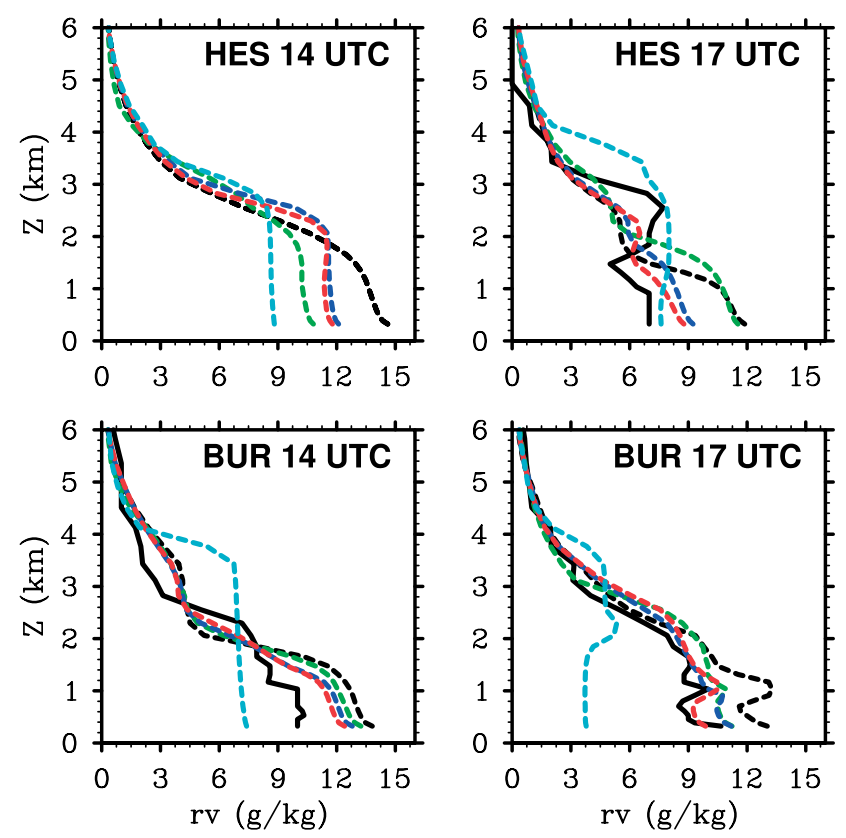

Figure 15. Time evolution of the potential temperature $(\mathrm{K})$ and moisture profiles $\left(\mathrm{g} \mathrm{kg}^{-1}\right)$, observed (thick black line) and simulated with ECMCTL (red), ARPCTL (green), ECMSM1 (blue), ECMSM2 (cyan) and ECMSM3 (magenta) in Heselbach (HES) and Burnhaupt (BUR). 

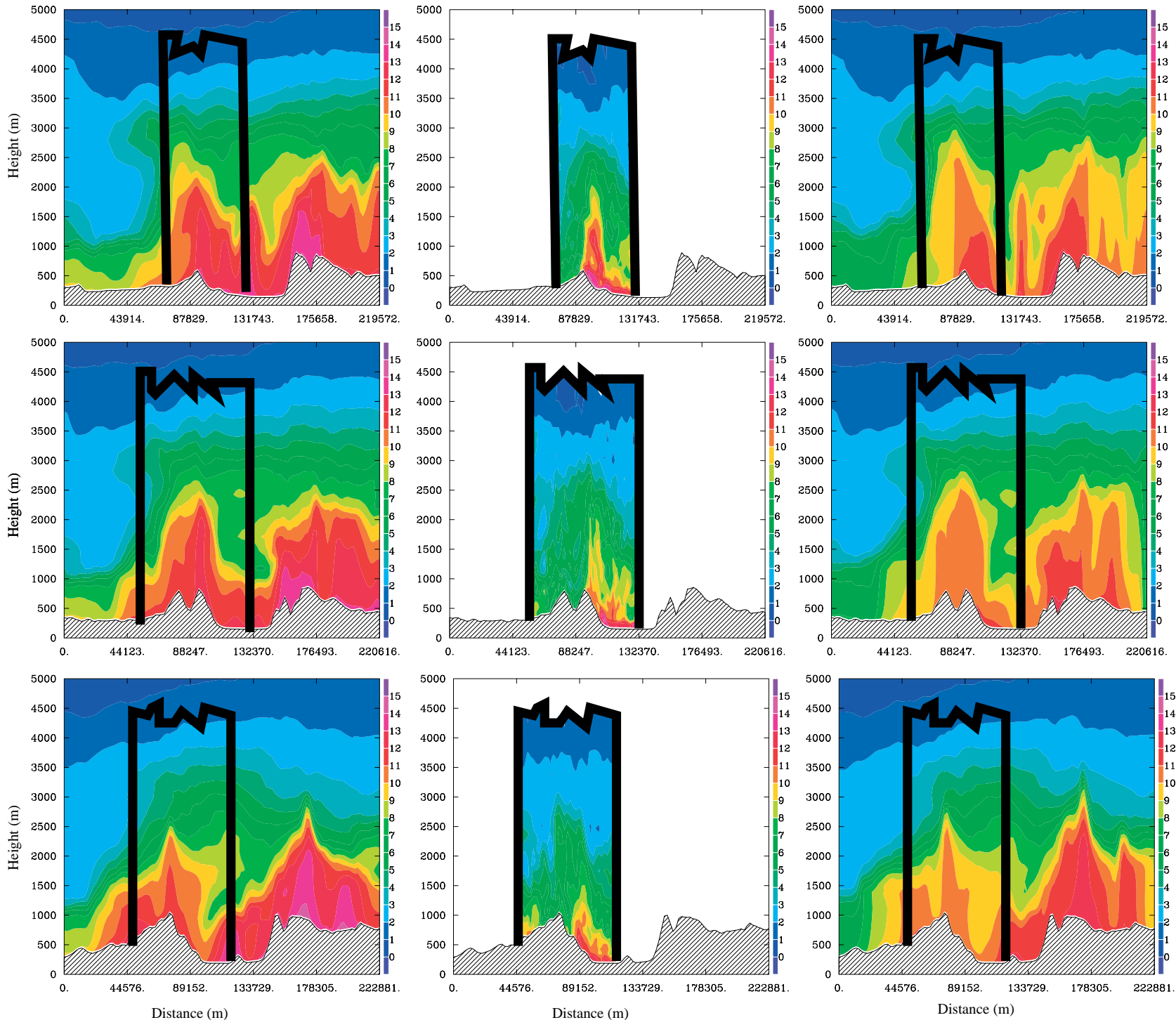

Figure 16. Vertical west-east cross-sections (displayed from north at top to south at bottom) of the water-vapour mixing ratio ( $\mathrm{g} \mathrm{kg}^{-1}$ ) measured with LEANDRE (centre) and computed in ECMCTL (left) and in ECMSM1 (right). See Figure 10(b) or (d) for the location of the cross-sections. This figure is available in colour online at wileyonlinelibrary.com/journal/qj

intensities are reduced by half both in precipitation rate and vertical velocity but it is interesting to note that, despite a similar amplitude in vertical velocity and precipitation intensity, the storm occurs much earlier in ECMSM3 than in ECMSM2. Among the different simulations, the averaged accumulated precipitation within the box area varies from $0.24,0.18,0.08,0.05$, to $0.05 \mathrm{~mm}$ for ARPCTL, ECMCTL, ECMSM1, ECMSM2 and ECMSM3. It is also important to note that, in all the experiments, the cloud-top height exceeds $12 \mathrm{~km}$ of altitude (not shown).

These various experiments reveal non-trivial interplay between the storm development and both the structure and the intensity of the initial moisture field. The comparisons between ECMCTL, ECMSM2 and ECMSM3 (same spatial distribution but different amplitudes of the surface moisture) indicate that the storm intensity and duration are significantly reduced as surface moisture decreases. However, when the surface moisture is modified in both its spatial distribution and its intensity, as it is the case in ECMSM1 with respect to ECMCTL, model results show only a minor reduction of the storm duration in spite of the much drier surface condition imposed in ECMSM1.

\section{Conclusion}

The COPS field experiment took place in summer 2007 over northeastern France and southwestern Germany in a region of moderate orography including the Vosges and Black Forest mountains. During the unusually perturbed 2007 summer, the case of 15 July provided one of the rare opportunities to observe and document thermally forced convection. In spite of not very propitious instability conditions, a convective line developed over the southern Black Forest in the early afternoon, evolving into a shortlived, very localized storm. This event was found difficult to capture by most of the various high-resolution convectionpermitting models used in real time during the field campaign but the Meso-NH forecast appeared to be quite skilful. Meso-NH was able to capture the storm development (initiation time and triggering location) as well as its time evolution (duration and propagation direction) quite accurately. 

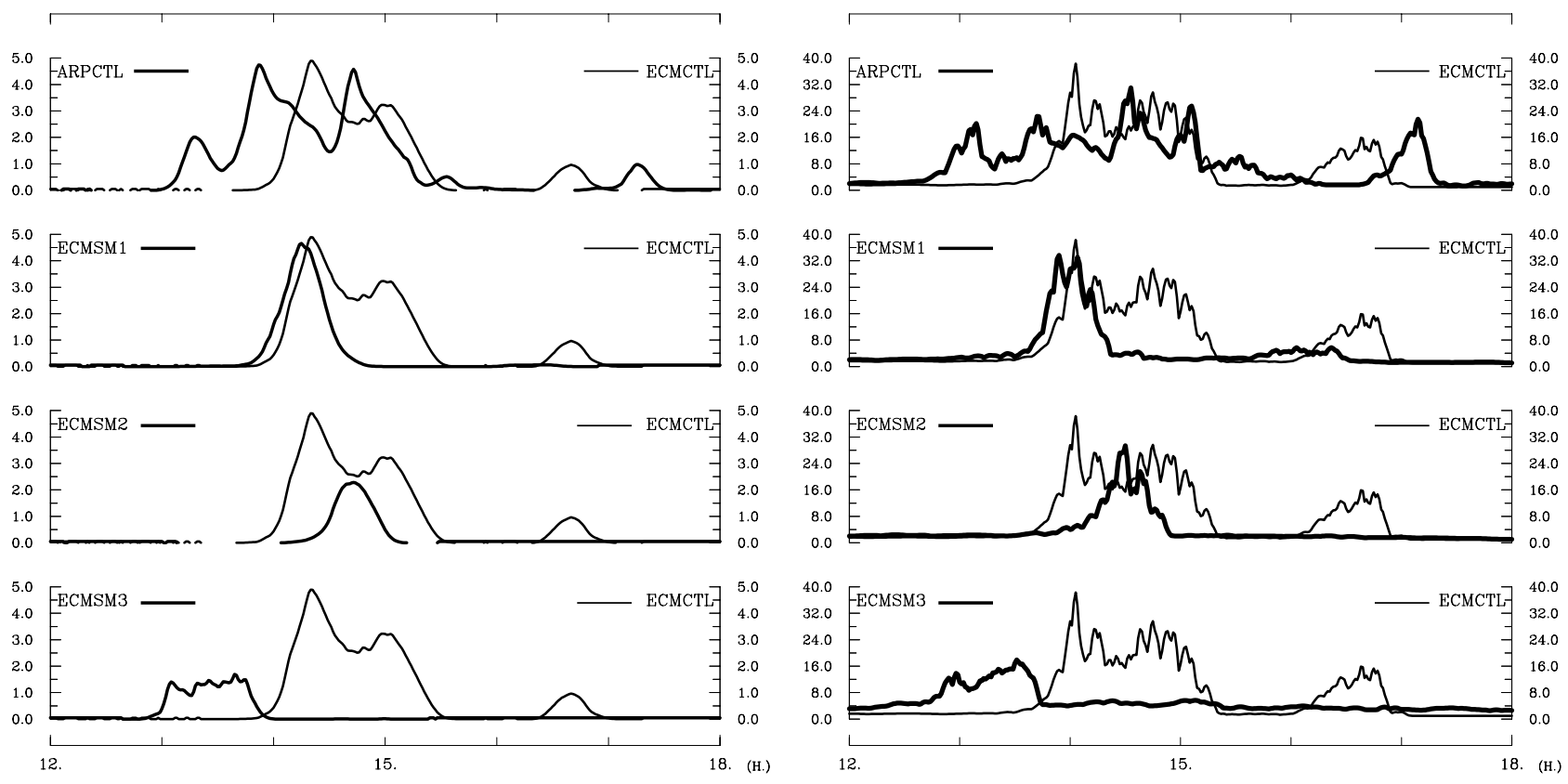

Figure 17. Time evolution of the spatially averaged instantaneous precipitation rate (left, in mm day ${ }^{-1}$ ) and maximum vertical velocity (right, in $\mathrm{m} \mathrm{s}^{-1}$ ) within a box centred over the Black Forest storm. The thin lines correspond to the results of ECMCTL whereas the results of the sensitivity experiments (ARPCTL, ECMSM1, ECMSM2 and ECMSM3 from top to bottom) are represented by thick lines.

To identify better the factors leading to such a good forecast, the Meso-NH model results were further assessed by comparison with the various and numerous observations collected during COPS, the goal being to find out to what extent this good forecast was obtained for good reasons. In the absence of strong upper-level forcing, convection triggering is expected to be controlled by three main factors: the air-mass potential instability, the moisture supply and the vertical motion resulting from orographic lifting and/or thermal forcing. These three factors were successively examined in view of the available observations. The CAPE and CIN parameters used to characterize the level of instability did not show any major inconsistency between model and observations but, unfortunately, none of the available soundings was located very close to where the storm started. In the model, the vertical motion was found to result from the combination of thermal and orographic forcing: the up-slope motion induced by the solar heating was reinforced by a low-level convergence line, which developed in the lee of the southern Black Forest peak. The clear-air observations of the Feldberg Doppler radar fully support this scenario. The assessment of the moisture supply was based upon the soundings but also on various airborne lidar measurements providing unique spatial coverage. With respect to the latter factor, model results were found to be not quite accurate and exhibited significant moist biases in the $1000-3000 \mathrm{~m}$ layer and also within the PBL. In altitude, the bias originated from too slow a progression of a dry layer entering the domain from the northwest. It is therefore unlikely that it could have affected the storm forecast. The PBL bias, which was especially strong in the south of the domain, was more problematic. Accompanied by a slight cold bias in temperature, it could have favoured convection development. This is why the case study was analyzed further by carrying out a series of sensitivity experiments.
The sensitivity studies were guided by the results of a twin experiment initialized with ARPEGE analysis instead of ECMWF analysis, which produced even more convective developments but with more accurate behaviour of the PBL. Detailed inspection of the analyses revealed that a major difference lay in the initial superficial soil moisture, globally half as moist in the ARPEGE analysis as in the ECMWF analysis. Therefore, a series of experiments was performed in the aim of assessing the sensitivity of the storm forecast to the initial surface moisture field. In the experiments for which the initial superficial moisture was reduced by first $20 \%$ and then $50 \%$, the Black Forest storm still occurred but its intensity was weaker and its duration shorter. A $20 \%$ reduction significantly improved the PBL structure by removing the slight cold temperature bias and strongly diminishing the moist bias whereas, with a $50 \%$ reduction, the PBL structure became unrealistically warm, dry and high. The best results were obtained for an experiment in which the ECMWF initial soil moisture was substituted by the ARPEGE one. In this experiment, the PBL structure was in fairly good agreement with observations and the Black Forest storm was still well depicted.

These experiments highlighted the role of the initial surface moisture in modulating the development of convection and may partly explain the failure of some other forecasts. However, bearing in mind that all our experiments, including the one with the driest surface initial moisture, produced deep convection, it is more likely that the key parameters for a satisfactory forecast are to be found more in the ability of the model to accurately reproduce the dynamical forcing (especially the convergence line) than in the characteristics of the air-mass stability.

\section{Acknowledgements}

The support of WWRP (World Weather Research Program) in the scientific planning of COPS and the excellent 
collaboration with the D-PHASE modelling community were greatly appreciated. COPS is a component of Priority Program 1167 funded by the German Research Foundation. COPS was further supported by CNRS/INSU (Institut des Sciences de l'Univers), CNES (Centre National de la Recherche Spatiale), ANR (Agence Nationale pour la Recherche) and Météo-France, and also by the Austrian Science Foundation (FWF) and the University of Vienna. The authors thank SAFIRE (Service des Avions Français Instrumentés pour la Recherche en Environnement, www.safire.fr), the Institut Géographique National (IGN, www.ign.fr) and the Division Technique of INSU (DT/INSU, www.dt.insu.cnrs.fr) for preparing and delivering the research aircraft (Falcon 20/F-GBTM) and the airborne instruments in a timely manner for COPS. The authors are grateful to D. Bruneau and P. Genau (LATMOS), F. Blouzon, A. Abchiche and N. Amarouche (DT/INSU) for re-fitting and operating the LEANDRE 2 system in the F/F20. Computational resources were provided by Institut du Développement des ressources en Informatique Scientifique (IDRIS, project 090569-CP1). Two anonymous reviewers and the associate editor are thanked for their helpful comments. Many thanks also to Pierre Tabary and Claudine Guegen from MétéoFrance for their assistance with radar data and to many COPS scientists for stimulating discussions on the case studied, especially Jörg Trentmann, Norbert Kalthoff, Ralph Burton, Alan Gadian, Andreas Behrendt and Hans Volkert.

\section{References}

Agusti-Panareda A, Vasiljevic D, Beljaars A, Bock O, Guichard F, Nuret M, Garcia Mendez A, Ansersson E, Bechthold P, Fink A, Hersbach H, Lafore JP, Ngamini JB, Parker D, Redelsperger JL, Tompkins A. 2009. Radiosonde humidity bias correction over the West African region for the special AMMA reanalysis at ECMWF. Q. J. R. Meteorol. Soc. 135: 595-617.

Asselin R. 1972. Frequency filter for time integrations. Mon. Weather Rev. 100: 487-490.

Aydin K, Seliga TA, V B. 1986. Remote sensing of hail with a dual linear polarisation radar. J. Appl. Meteorol. 25: 1475-1484.

Banta R. 1990. Atmospheric processes over complex terrain. AMS Meteorol. Monographs 23: 229-283.

Barthlott C, Schipper J, Kalthoff N, Adler B, Kottmeier C, Blyth A, Mobbs S. 2010. Model representation of boundary-layer convergence triggering deep convection over complex terrain: A case study from COPS. Atmos. Res. 95: 172-185.

Barthlott C, Burton R, Kirshbaum D, Hanley K, Richard E, Chaboureau J-P, Trentmann J, Kern B, Bauer H-S, Schwitalla T, Keil C, Seity Y, Gadian A, Blyth A, Mobbs S, Flamant C, Handwerker J. 2011. Initiation of deep convection at marginal instability in an ensemble of mesoscale models: a case study from COPS. Q. J. R. Meteorol. Soc. 137(S1): 118-136, DOI: 10.1002/qj.707.

Bechtold P, Bazile E, Guichard F, Mascart P, Richard E. 2001. A mass flux convection scheme for regional and global models. Q. J. R. Meteorol. Soc. 127: 869-886.

Behrendt A, Pal S, Aoshima F, Bender M, Blyth A, Corsmeier U, Cuesta J, Dick G, Dorninger M, Flamant C, Di Girolamo P, Gorgas T, Huang Y, Kalthoff N, Khodayar S, Mannstein H, Träumner K, Wieser A, Wulfmeyer V. 2011. Observation of convection initiation processes with a suite of state-of-the-art research instruments during COPS IOP 8b. Q. J. R. Meteorol. Soc. 137(S1): 81-100, DOI: 10.1002/qj.758.

Bhawar R, Di Girolamo P, Summa D, Flamant C, Althausen D, Behrendt A, Kiemle C, Bosser P, Cacciani M, Champollion C, Di Iorio T, Engelmann R, Herold C, Müller D, Pal S, Wirth M, Wulfmeyer V. 2011. The water vapour intercomparison effort in the framework of the Convective and Orographically-induced Precipitation Study: airborne-to-ground-based and airborne-to-airborne lidar systems. Q. J. R. Meteorol. Soc. 137(S1): 325-348, DOI: 10.1002/qj.697.
Bougeault P, Binder P, Buzzi A, Dirks R, Houze R, Kuettner J, Smith RB, Steinacker R, Volkert H. 2001. The MAP special observing period. Bull. Am. Meteorol. Soc. 82: 433-462.

Browning KA, Blyth AB, Clark PA, Corsmeier U, Morcrette CJ, Agnew JL, Ballard SP, Bamber D, Barthlott C, Bennett LJ, Beswick KM, Bitter M, Bozier KE, Brooks BJ, Collier CG, Davies F, Deny B, Dixon MA, Feuerle T, Forbes RM, Gaffard C, Gray MD, Hankers R, Hewison TJ, Kalthoff N, Khodayar S, Kohler M, Kottmeier C, Kraut S, Kunz M, Ladd DN, Lean HW, Lenfant J, Li Z, Marsham J, McGregor J, Mobbs SD, Nicol J, Norton E, Parker DJ, Perry F, Ramatschi M, Ricketts HMA, Roberts NM, Russell A, Schulz H, Slack EC, Vaughan G, Waight J, Wareing DP, Watson RJ, Webb AR, A W. 2007. The convection storm initiation project. Bull. Am. Meteorol. Soc. 88: 1939-1955.

Bruneau D, Quaglia P, Flamant C, Meissonnier M, J P. 2001. The airborne lidar LEANDRE II for water-vapor profiling in the troposphere. I. System description. Appl. Opt. 40: 3450-3475.

Chaboureau JP, Cammas JP, Mascart P, Pinty JP, Claud C, Roca R, Morcrette JJ. 2000. Evaluation of a cloud system life-cycle simulated by Meso-NH during FASTEX using METEOSAT radiances and TOVS-3I cloud retrievals. Q. J. R. Meteorol. Soc. 126: 1735-1750.

Chaboureau JP, Cammas JP, Mascart P, Pinty JP, Lafore JP. 2002. Mesoscale model cloud scheme assessment using satellite observations. J. Geophys. Res. 107(():D17): 4301. DOI:10.1029/2001JD000 714

Cosma S, Richard E, Miniscloux F. 2002. The role of small-scale orographic features in the spatial distribution of precipitation. Q. J. R. Meteorol. Soc. 128: 75-92.

Cuxart J, Bougeault P, Redelsperger JL. 2000. A turbulence scheme allowing for mesoscale and large-eddy simulations. Q. J. R. Meteorol. Soc. 126: $1-30$.

Depue T, Kennedy PC, Rutledge SA. 2007. Performance of the hail differential reflectivity polarimetric radar hail indicator. J. Appl. Meteorol. Climatol. 46: 1290-1301.

Di Girolamo P, Summa D, Ferretti R. 2009a. Rotational Raman lidar measurements for the characterization of stratosphere-troposphere exchange mechanisms. J. Atmos. Sci. 26: 1742-1762.

Di Girolamo P, Summa D, Lin RF, Maestri T, Rizzi R, Masiello G. 2009b. UV Raman lidar measurements of relative humidity for the characterization of cirrus cloud microphysical properties. Atmos. Chem. Phys. 9(:): 9799-8811.

Durran DR. 1989. Improving the anelastic approximation. J. Atmos. Sci. 46: 1453-1461.

Emanuel KA. 1994. Atmospheric convection. Oxford University Press: Oxford, UK.

Fritsch JM, Carbone RE. 2004. Improving quantitative precipitation forecasts in the warm season: A USWRP Research and Development Strategy. Bull. Am. Meteorol. Soc. 85: 955-965.

Höller H, Hagen M, Meischner PF, Bringi VN, Hubbert J. 1994. Life cycle and precipitation formation in a hybrid-type hailstorm revealed by polarimetric and Doppler radar measurements. J. Atmos. Sci. 51: $2500-2522$.

Johnson D, Flament P, Bernstein R. 1994. High-resolution satellite imagery for mesoscale meteorological studies. Bull. Am. Meteorol. Soc. 75: 5-33.

Kain JS, Fritsch JM. 1993. Convective parameterization for mesoscale models: the Kain-Fritsch Scheme. Meteorol. Monogr. 46: 165-170.

Kalthoff N, Adler B, Barthlott C, Corsmeier U, Mobbs S, Crewell S, Träumer K, Kottmeier C, Wieser A, Smith V, Di Girolamo P. 2009. The impact of convergence zones on the initiation of deep convection: A case study from COPS. Atmos. Res. 93: 680-694.

Kirshbaum DJ, Bryan GH, Rotunno R. 2007. The triggering of orographic rainbands by small-scale topography. J. Atmos. Sci. 64: 1530-1549.

Kottmeier C, Kalthoff N, Barthlott C, Corsmeier U, van Baelen J, Behrendt A, Behrendt R, Blyth A, Coulter R, Crewell S, Di Girolamo P, Dorninger M, Flamant C, Foken T, Hagen M, Hauck C, Höller H, Konow H, Kunz M, Mahlke H, Mobbs S, Richard E, Steinacker R, Weckwerth T, Wieser A, Wulfmeyer V. 2008. Mechanisms initiating deep convection over complex terrain during COPS. Meteorol. Z. 17. 931-948.

Lafore JP, Stein J, Asencio N, Bougeault P, Ducrocq V, Duron J, Fischer C, Héreil P, Mascart P, Masson V, Pinty JP, Redelsperger JL, Richard E, Vilà-Guerau de Arellano J. 1998. The Meso-NH Atmospheric Simulation System. Part I: Adiabatic formulation and control simulations. Scientific objectives and experimental design. Ann. Geophys. 16: 90-109.

Lascaux F, Richard E, Pinty JP. 2006. Numerical simulations of three different MAP IOPs and the associated microphysical processes. Q. J. R. Meteorol. Soc. 132: 1907-1926. 
Mesinger F, Arakawa A. 1976. Numerical methods used in atmospheric models. GARP Publication Series 17, Vol. I.

Noilhan J, Planton S. 1989. A simple parameterization of land surface processes for meteorological models. Mon. Weather Rev. 117: 536-549.

Phillips VT, Pokrovsky A, Khain A. 2007. The influence of timedependent melting on the dynamics and precipitation production in maritime and continental storm clouds. J. Atmos. Sci. 64: 338-359.

Pinty JP, Jabouille P. 1998. 'A mixed-phase cloud parameterization for use in a mesoscale non-hydrostatic model: simulations of a squall line and of orographic precipitations'. In Conf. on Cloud Physics, Everett, WA. Amer. Meteor. Soc.; pp 217-220.

Rotach M, Ambrosetti P, Ament F, Appenzeller C, Arpagaus M, Bauer HS, Bouttier F, Buzzi A, Corazza M, Davolio S, Denhard M, Dorninger M, Fontannaz L, Frick J, Fundel F, Germann U, Gorgas T, Hegg C, Hering A, Keil C, Liniger M, Marsigli C, McTaggart-Cowan R, Montani A, Mylne K, Ranzi R, Richard E, Rossa A, Santos-Muoz D, Schär C, Seity Y, Staudinger M, Stoll M, Volkert H, Walser A Wang Y, Werhahn J, Wulfmeyer V, Zappa M. 2009. MAP D-PHASE: Real-time demonstration of weather forecast quality in the Alpine region. Bull. Am. Meteorol. Soc. 90: 1321-1336.

Schwitalla T, Bauer HS, Wulfmeyer V, Zängl G. 2008. Systematic errors of QPF in low-mountain regions as revealed by MM5 simulations. Meteorol. Z. 17: 903-919.

Stein J, Richard E, Lafore JP, Pinty JP, Asencio N, Cosma S. 2000. High-resolution non-hydrostatic simulations of flash-flood episodes with grid-nesting and ice-phase parameterization. Meteorol. Atmos. Phys. 72: 203-221.

Volkert H, Schär C, Smith R (eds). 2007. Special section 'MAP findings'. Q. J. R. Meteorol. Soc. 133: 809-967.
Weckwerth T, Parsons DB, Koch SE, Moore JA, LeMone MA, Demoz BB, Flamant C, Geerts B, Wang J, F FW. 2004. An overview of the International H2O Project (IHOP-2002) and some preliminary highlight. Bull. Am. Meteorol. Soc. 85: 253-277.

Wulfmeyer V, Behrendt A, Bauer HS, Kottmeier C, Corsmeier U, Blyth A, Craig G, Schumann U, Hagen M, Crewell S, Di Girolamo P, Flamant C, Miller M, Montani A, Mobbs S, Richard E, Rotach M, Arpagaus M, Russchenberg H, Schlüssel P, König M, Gärtner V, Steinacker R, Dorninger M, Turner D, Weckwerth T, Hense A, Simmer C. 2008. The Convective and Orographically-induced Precipitation Study (COPS): A research project for improving quantitative precipitation forecasting in low-mountain regions. Bull. Am. Meteorol. Soc. 89: 1477-1486.

Wulfmeyer V, Behrendt A, Kottmeier C, Corsmeier U, Barthlott C, Craig G, Hagen M, Althausen D, Aoshima F, Arpagaus M, Bauer HS, van Baelen J, Bennett L, Blyth A, Brandau C, Champollion C, Crewell S, Dick G, Dorninger M, Dufournet Y, Eigenmann R, Engelmann R, Flamant C, Foken T, Di Girolamo P, Groenemeijer P, Gorgas T, Grzeschik M, Peters G, Handwerker J, Hauck C, Höller H, Junkermann W, Kalthoff N, Kiemle C, König M, Krauss L, Long C, Madonna F, Mobbs S, Neininger B, Pal S, Pigeon G, Richard E, Rotach MW, Russchenberg H, Schwitalla T, Smith V, Steinacker R, Trentmann J, Turner DD, Vogt S, Volkert H, Weckwerth T, Wernli H, Wieser A. 2011. The Convective and Orographically-induced Precipitation Study (COPS): The scientific strategy, the field phase, and first highlights. Q. J. R. Meteorol. Soc. 137(S1): 3-30, DOI: 10.1002/qj.752.

Zängl G. 2002. An improved method for computing horizontal diffusion in a sigma-coordinate model and its application to simulations over mountainous topography. Mon. Weather Rev. 130: 1423-1432. 